NBER WORKING PAPER SERIES

OPTIMAL PORTFOLIO CHOICE WITH WAGE-INDEXED SOCIAL SECURITY

\author{
Jialun Li \\ Kent Smetters \\ Working Paper 17025 \\ http://www.nber.org/papers/w17025
}

NATIONAL BUREAU OF ECONOMIC RESEARCH

1050 Massachusetts Avenue

Cambridge, MA 02138

May 2011

This research was supported by the U.S. Social Security Administration through a grant to the National Bureau of Economic Research as part of the SSA Retirement Research Consortium. The findings and conclusions expressed are solely those of the author(s) and do not represent the views of SSA, any agency of the Federal Government, or the NBER. This paper is based, in part, on an earlier project with Ying Chen.

NBER working papers are circulated for discussion and comment purposes. They have not been peerreviewed or been subject to the review by the NBER Board of Directors that accompanies official NBER publications.

(C) 2011 by Jialun Li and Kent Smetters. All rights reserved. Short sections of text, not to exceed two paragraphs, may be quoted without explicit permission provided that full credit, including $\odot$ notice, is given to the source. 
Optimal Portfolio Choice with Wage-Indexed Social Security

Jialun Li and Kent Smetters

NBER Working Paper No. 17025

May 2011

JEL No. G11,H0

\begin{abstract}
$\underline{\text { ABSTRACT }}$
This paper re-examines the classic question of how a household should optimally allocate its portfolio between risky stocks and risk-free bonds over its lifecycle. We show that allowing for the wage indexation of social security benefits fundamentally alters the optimal decisions. Moreover, the optimal allocation is close to observed empirical behavior. Households, therefore, do not appear to be making large "mistakes," as sometimes believed. In fact, traditional financial planning advice, as embedded in "target date" funds - whose enormous recent growth has been encouraged by new government policy - often leads to even relatively larger "mistakes" and welfare losses.
\end{abstract}

\title{
Jialun Li
}

3620 Locust Walk

Philadelphia, PA 19104

jialunli@wharton.upenn.edu

Kent Smetters

University of Pennsylvania

SH-DH 3303

3620 Locust Walk

Philadelphia, PA 19104

and NBER

smetters@wharton.upenn.edu 


\section{Introduction}

A considerable literature has examined how households should optimally allocate their savings between stocks and bonds over their lifecycle. Samuelson (1969) and Merton (1969) first addressed this problem in discrete and continuous time, respectively, assuming complete markets without labor income. Merton (1971) then introduced deterministic labor income into the continuous time framework while Bodie, Merton and Samuelson (1992) allowed for it to be elastically supplied. In more recent years, attention has shifted toward examining how the presence of uninsurable labor income risk and uncertain lifespans might impact savings and portfolio allocations over the life cycle. ${ }^{1}$

It is well known, though, that the actual portfolio decisions made by households are not consistent with standard expected-utility model. Households could, therefore, be making large mistakes and suffering significant welfare losses.

The standard expected utility model predicts a very high stock allocation (near 100\% or even exceeding $\mathrm{it}^{2}$ ) early in life that declines with age as human capital depreciates. When a simple representation of a social security system is included in the model, the optimal allocation is then often " $U$ shaped" in age, caused by an inflection point that emerges at the point of retirement. ${ }^{3}$ The homotheticity property of the standard model also leads to a similar lifetime stock-bond allocation across varying levels of permanent income. ${ }^{4}$

In contrast, the actual empirical evidence suggests three stylized facts: (I) the portfolio share in equities is much less than $100 \%$ for most households; (II) the portfolio's equity share tends to be "hump shape" $(\cap)$ in age; and (III) the lifetime poor tend to invest less in equities than richer households. ${ }^{5}$

\footnotetext{
${ }^{1}$ See Bertaut and Haliassos (1997); Gakidis (1998); Storesletten, Telmer, and Yaron (2000, 2007); Viceira (2001); Bodie, Detemple, and Walter (2004); Benzoni, Collin-Dufresne and Goldstein (2004); Cocco, Gomes and Maenhout (2005) and Gomes and Michaelides (2005). Related papers by Balduzzi and Lynch (1997), Brennan and Xia (1998), Campbell and Viceira (1999), and Kim and Omberg (1996) study the effects caused by the changes of riskfree interest rate or equity premium over the time. Carroll (2002) and Campbell and Cochrane (1999) propose models in which risk aversion varies with wealth.

${ }^{2}$ See, for example, Ayres and Nalebuff (2008).

${ }^{3}$ These models tie the social security benefit to an individual's final year of earnings prior to retirement to simplify the state space. That background risk is suddenly eliminated upon reaching retirement, creating an immediate reversal of the allocation.

${ }^{4}$ The homothetic property, however, is the easiest to break by including borrowing constraints or a social security system with a flat benefit that does not scale to permanent income.

${ }^{5}$ See Ameriks and Zeldes 2000, Heaton and Lucas 2000, and Poterba and Samwick, 2002.
} 
Several modifications to the standard model have been proposed in the past to deal with or more of these empirical facts. These alterations include the addition of liquidity constraints (Brown 1990; Ameriks and Zeldes 2000), saving for illiquid assets such as a house (Faig and Shum 2002), habit persistence utility (Polkovnichenko, 2007), and, incomplete trading markets between generations in a real business cycle economy where wages and stock returns are perfectly correlated (Storesletten, Telmer, and Yaron, 2007).

The current paper returns to the standard expected utility framework and simply considers the impact of a more detailed modeling of the social security system. For a majority U.S. households, the U.S. Social Security program is their largest source of retirement income (Social Security Administration 2002). Incorporating the key details of the system, therefore, could be quite important.

One key feature that has been missing in previous analyses is the wage-indexation of social security benefits. (We also more fully model the progressive nature of benefits.) In particular, when determining a pensioner's initial benefit level at retirement, the retiree's past wages are adjusted upward by wage-indexed factors that track the growth in the economywide average wage over time. Wage indexation is, therefore, naturally exposed to some of the same productivity shocks that influence stock returns over long periods of time. Even though a single person's own wage, which includes all sorts of idiosyncratic shocks, is poorly correlated with stock returns, the economy-wide average wage is empirically more highly correlated, especially over the longer periods of time that are most relevant for computing social security benefits. Wage indexation, therefore, causes a potentially strong low-frequency correlation with stock returns for young savers, which becomes less correlated as they age. The presence of this large unchosen wage-indexed pension asset, as we show, fundamentally alters the household decision rules over their lifecycle.

Our study focuses on the "optimal” lifecycle portfolio allocation (normative analysis). Our intention is not to explain the empirical evidence per se (positive analysis). Nonetheless, it is interestingly that the optimal allocations that we find are not so different from actual empirical behavior under reasonable parameter assumptions. In fact, we find that the "errors" being made by households often produce smaller welfare losses in our model relative to the standard advice given by financial planners. This standard advice has been recently 
incorporated into popular "target date" mutual funds. These funds have grown enormously in popularity during the past six years, encouraged by recent government policy. While this policy might improve welfare for some households, it appears to decrease it for many others.

\section{Empirical Evidence}

Although our study primarily focuses on determining the optimal stock-bond portfolio over the lifecycle, it is helpful to start with an overview of the actual behavior of U.S. households as background. The Survey of Consumer Finances (SCF) is generally considered the best data source for reporting the financial wealth of U.S. families. It provides comprehensive coverage of different measures of wealth as well as key characteristics (age, education, etc.) that tend to be correlated with wealth. The SCF is conducted every three years with different families; we report evidence from sample in 2004. ${ }^{6}$ However, as Ameriks and Zeldes (2000) warn, the exact magnitude of these estimates should be taken with a "grain of salt" due to data definitions and other issues. Appendix A describes the definitions and variables from SCF 2004 that we use in our empirical estimation.

Figure 1 reports the average (mean) percent of a household's portfolio invested in risky stocks by age for families in which the "household head" (primary earner) falls into one of three different education groups: "No High School” education; with "High School” education only; with “College” education. Households are grouped into five-year "age buckets” in order to increase the sample size per cell. Figure 1 reveals the three key stylized facts: (I) the portfolio share in equities is much less than $100 \%$ for most households; (II) the portfolio's equity share tends to be "hump shape" $(\cap)$ in age; and (III) the lifetime poor tend to invest less in equities than richer households.

Figure 2 reports the average of total wealth relative to total (labor) income for these same education groups, respectively. Overall, wealth-income ratios increase with age and education. The age-shape of the accumulation profiles also suggest a significant bequest motive that is increasing in the education class. However, the exact steepness post-retirement

\footnotetext{
${ }^{6}$ The SCF is a non-panel data dataset that uses a dual-frame sample design. One part is selected to obtain a sufficiently large and unbiased sample. The other part is designed to disproportionately select wealthier families. We use the provided weights to adjust the unequal probabilities of selection in the survey and for nonresponse.
} 
Figure 1: Stock Allocation from SCF2004

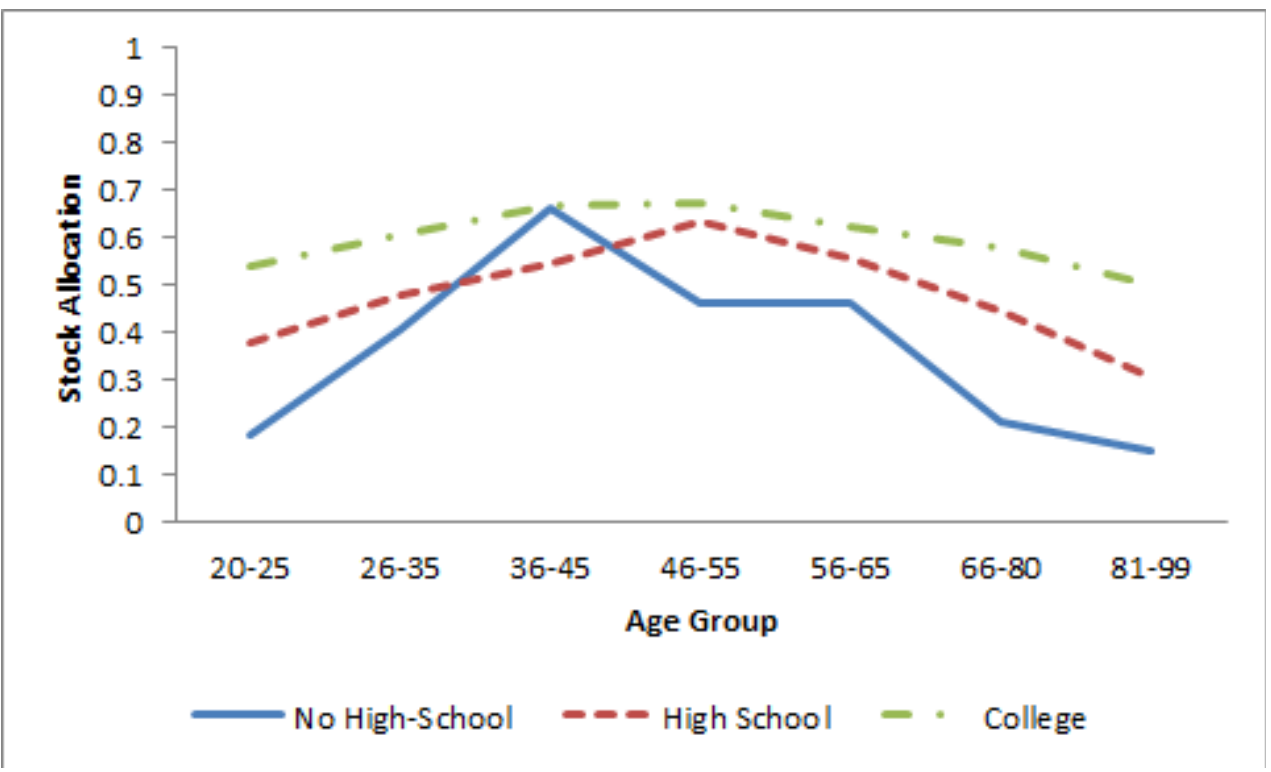

Figure 2: Wealth/Income Ratio from SCF2004

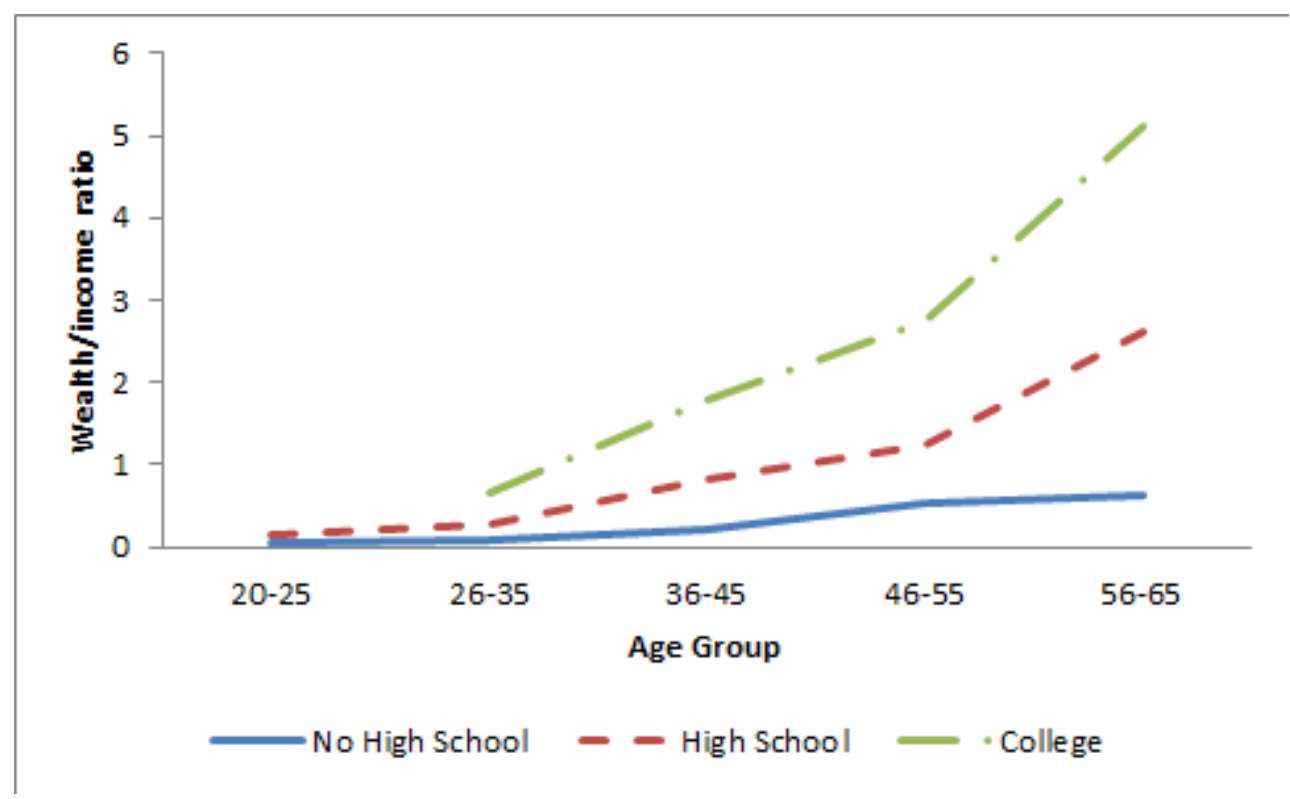


should also be taken with a "grain of salt" due to potential survivor bias where wealthier households tend to live longer on average.

We calibrate our model across different education groups using the population weighted average wealth-income ratios presented in Figure 2. We then report how our resulting simulated portfolio allocations compare with the evidence shown in Figure 1. This approach to calibration purposely reduces our ability to pick the model's deep structural parameters in order to try to simply match Figure 1 . We will demonstrate that the stylized facts presented in Figure 1 are potentially quite consistent with optimal decision rules within a standard expected utility framework that is augmented with a wage-indexed social security system.

\section{Specification of the Model}

We now present a lifecycle portfolio choice model with standard preferences where households face uncertain wage earnings. Individuals make their consumption, saving and portfolio decisions over risk-free bonds and risky stocks at the beginning of each period. Their savings and portfolio choices are motivated by three main factors: precautionary savings in the presence of incomplete insurance markets; consumption needs during retirement; and, a joy-of-giving desire to leave a bequest. Individuals also pay a mandatory social security tax during their working years in exchange for a benefit during retirement.

\subsection{Preferences}

Each individual $i$ works from age $t_{0}$ to retirement age $M$. The maximum length of life is $T$ and $p_{t}$ is the probability that the individual is still alive at age $t+1$ conditional on being alive at age $t$. Preferences take the standard Constant Relative Risk Aversion (CRRA) form and are additively separable over time. The household's maximum expected utility at $t_{0}$ is

$$
\max E_{t_{0}} \sum_{t=t_{0}}^{T} \beta^{t-t_{0}}\left(\prod_{j=t_{0}-1}^{t-2} p_{j}\right)\left(p_{t-1} \frac{C_{i, t}^{1-\gamma}}{1-\gamma}+b\left(1-p_{t-1}\right) \frac{W_{i, t}^{1-\gamma}}{1-\gamma}\right)
$$

where $\beta<1$ is the weight placed on future utility, $C_{i, t}$ is $i$ 's consumption at age $t$, and $\gamma$ is the coefficient of relative risk aversion. $W_{i, t}$ is the wealth (bequest) left at the time of the death where $b$ represents the intensity of the bequest motive. 


\subsection{Financial Assets}

Investors have access to two investment instruments: risk-free bonds and risky stocks. The riskless bonds pay a constant gross real return $R_{f}$, while the risky asset pays a gross real return $R_{t}^{S}$ :

$$
R_{t}^{S}=R^{f}+\mu+\eta_{t}
$$

where $\mu$ is the deterministic equity premium and $\eta_{t}$ is the innovation to this excess return at time $t . \quad \eta_{t}$ is independently and identically distributed (i.i.d.) over time and normally distributed $N\left(0, \sigma_{\eta}\right)$.

\subsection{Labor Income}

Similar to Carroll (1997), Gourinchas and Parker (2002), Cocco, Gomes and Maenhout (2005), and several other papers, exogenous labor income for agent $i$ at time $t$ is modeled as

$$
\begin{aligned}
Y_{i, t} & =\exp \left(y_{i, t}\right) \quad \text { with probability } 1-\lambda \\
& =0 \quad \text { with probability } \lambda
\end{aligned}
$$

where $\lambda$ is the probability of being unemployed. Before retirement, log income is composed of three terms:

$$
y_{i, t}=g\left(t, F_{i, t}\right)+\omega_{i, t}+z_{i, t}
$$

where $g\left(t, F_{i, t}\right)$ is a deterministic function of age $t$ and other individualistic characteristics $F_{i, t}$. The term $\omega_{i, t}$ is an idiosyncratic i.i.d. normally distributed shock $N\left(0, \sigma_{\omega}\right)$. The variable $z_{i, t}$ is a permanent first-order autoregressive shock:

$$
z_{i, t}=\theta z_{i, t-1}+\xi_{t}+\phi_{i, t}
$$

with an autocorrelation coefficient equal to $\theta$, an aggregate (economy-wide) component $\xi_{t}$ distributed i.i.d. $N\left(0, \sigma_{\xi}\right)$, and an idiosyncratic component $\phi_{i, t}$ distributed i.i.d. $N\left(0, \sigma_{\phi}\right)$. We also allow the correlation between the innovation to excess stock returns $\eta_{t}$ and the aggregate labor income shock $\xi_{t}$ to equal $\rho_{\xi \eta}$ so that $\eta_{t}$ and $\xi_{t}$ are jointly bivariate distributed 
(see Appendix B).

Individuals pay a flat social security tax rate of $\tau_{S S}$ through their working years plus a nonlinear labor income tax rate $\tau_{w}$ that is calibrated below. The (net of tax) disposable labor income at time $t$ for individual $i$, therefore, is:

$$
\begin{aligned}
Y_{i, t}^{d} & =\left(1-\tau_{S S}\right)\left(1-\tau_{w}\left[Y_{i, t}\right]\right) Y_{i, t} \text { for } t<M \\
& =0 \text { for } t \geq M
\end{aligned}
$$

\subsection{Wage-Indexed Social Security}

In the United States, a retiree's initial Social Security benefit level is calculated by first multiplying each year of his or her previous wage by the relevant wage-indexed factor. This factor tracks the average wage growth experienced across the entire economy since the year in which that particular wage was earned. For example, suppose that you retired today and you earned \$30,000 twenty years ago. Also suppose that the average wage in the economy grew on average 5\% (nominal) per year during the past 20 years. Your recorded wage of $\$ 30,000$ would, therefore, be multiplied upward by a factor of $1.05^{20}=2.65$, to create a wage representation of $\$ 79,598.93$ today. Similar wage factors are applied to each of your other previous wages. Your individual Average Indexed Yearly Earnings (AIYE) is then set equal to the average of these adjusted wages. ${ }^{7}$ Progressivity is then introduced by calculating your Primary Insurance Amount (PIA) using a nonlinear (convex) function of your AIYE. Your PIA then forms the basis of your Social Security benefit amount before some additional adjustments are made (e.g., a spousal benefit). ${ }^{8}$

Empirically, these wage-index factors are highly correlated with stock returns over time. At first glance, this fact might be surprising since wages and stock returns are not highly correlated at "high frequency" (e.g., yearly) even at the sectorial level where some of the idiosyncratic component has already been removed (e.g., Davis and Paul 2000). However,

\footnotetext{
${ }^{7}$ Technically speaking, in the United States, this calculation is done at monthly (not yearly) frequency to calculuate the Average Indexed Monthly Earnings (AIME). Moreover, only the best "best 35" years of earnings - those with the larged adjusted wages - are included in the AIME. We ignore these finer details in order to keep the state space more manageable. The U.S. system also has a cap on yearly wages subject to the payroll tax, and the AIME is, therefore, calculated over capped wages. Our calculations include this cap.

${ }^{8}$ Individuals with a larger AIYE receive a larger PIA, thereby recognizing that they paid more into the system. However, the PIA / AIYE ratio - the "replacement rate" - is a declining function of the AIYE so that the lifetime poor receives a relatively larger replacement rate of their previous earnings.
} 
idiosyncratic (including sector-specific) risks tend to cancel inside of the economy-wide average wage-index factor used by Social Security. Moreover, wage factors are often calculated at a very "low frequency," especially for wages earned early in the lifecycle. The economywide average wage and stock returns are much more highly correlated at this low frequency (Jermann, 1999). ${ }^{9}$

Returning to our model framework, social security benefits received at the point of retirement at age $M$ are a function of an individual's Average Indexed Yearly Earnings (AIYE) during their working years. The AIYE is calculated by adjusting upward each wage earned by individual $i$ during the previous year $t$ by the growth in the aggregate (economy-wide) average wage between year $t$ and the retirement year, $M$. Denote $Y_{t}^{A}$ as the aggregate average wage level at time $t$. The appropriate wage index adjustment factor for wages earned in year $t$, therefore, equals $\frac{Y_{M}^{A}}{Y_{t}^{A}}$, which is the cumulative growth in aggregate wages between times $t$ and $M$. Individual $i$ 's AIYE at the point of retirement, therefore, is equal to the sum of all previous wages adjusted upward by their respective wage index factors, divided by the number of working years:

$$
\begin{aligned}
\bar{Y}_{i, M} & =\frac{Y_{i, t_{0}} \frac{Y_{M}^{A}}{Y_{t_{0}}^{A}}+Y_{i, t_{0}+1} \frac{Y_{M}^{A}}{Y_{t_{0}+1}^{A}}+\cdots+Y_{i, M-1} \frac{Y_{M}^{A}}{Y_{M-1}^{A}}}{M-t_{0}} \\
& =\frac{\left(\left(Y_{i, t_{0}} \frac{Y_{t_{0}+1}^{A}}{Y_{t_{0}}^{A}}+Y_{i, t_{0}+1}\right) \frac{Y_{t_{0}+2}^{A}}{Y_{t_{0}+1}^{A}}+Y_{i, t_{0}+2}\right) \cdots}{M-t_{0}}
\end{aligned}
$$

The aggregate wage level is modeled as a first-order autoregressive process with a unitroot in logs:

$$
Y_{t+1}^{A}=Y_{t}^{A} \cdot \exp \xi_{t+1}
$$

which we can rewrite as:

$$
\frac{Y_{t+1}^{A}}{Y_{t}^{A}}=\exp \xi_{t+1}
$$

We can then track individual $i$ 's AIYE at each age based on his AIYE in the previous age

\footnotetext{
${ }^{9}$ This result is consistent with a neoclassical model with shocks to productivity and depreciation.
} 
with the additional of just one state variable:

$$
\bar{Y}_{i, t+1}=\frac{\left(t-t_{0}\right) \bar{Y}_{i, t} \cdot \exp \xi_{t+1}+Y_{i, t+1}}{t-t_{0}+1}
$$

Social security benefits at retirement, therefore, are a function of individual $i$ 's AIYE:

$$
\begin{aligned}
S S_{i, t} & =Q\left(\bar{Y}_{i, M}\right) \text { for } t \geq M \\
& =0 \text { for } t<M
\end{aligned}
$$

where $Q()$ is a nonlinear function calibrated to the U.S. Social Security system (discussed below).

The correlation between the aggregate average wage and stock returns, therefore, is $\rho_{\xi \eta}=\frac{\operatorname{cov}\left(\xi_{t}, \eta_{t}\right)}{\sigma_{\xi} \cdot \sigma_{\eta}}$. However, the correlation between individual $i$ 's (log) wage and stock returns is approximately one-fourth of the size due to additional idiosyncratic risk that is present in the individuals wage:

$$
\rho_{y \eta}=\frac{\operatorname{cov}\left(\xi_{t}, \eta_{t}\right)}{\sigma_{\eta} \cdot \sqrt{\sigma_{\xi}^{2}+\sigma_{\phi}^{2}+\sigma_{\omega}^{2}}} \approx \frac{\operatorname{cov}\left(\xi_{t}, \eta_{t}\right)}{\sigma_{\eta} \cdot \sqrt{16 \cdot \sigma_{\omega}^{2}}}=\frac{\operatorname{cov}\left(\xi_{t}, \eta_{t}\right)}{4 \cdot \sigma_{\xi} \cdot \sigma_{\eta}}
$$

The distinction between these correlations allows us to increase the aggregate average wage correlation with stocks (without the idiosyncratic terms) to a larger low-frequency value while preserving a much smaller correlation value that households individually face at high frequency (with idiosyncratic terms). ${ }^{10}$

\subsection{Optimization Problem}

As in several previous papers, we treat the share of income spent on housing, $h_{t}$, as an “above-the-line” expense (in both model and data) that exogenously reduces disposable income. In each period $t$, individual $i$ has some "cash on hand" denoted as $X_{i, t}$, which is composed of the following resources: wealth $W_{i, t}$ at the beginning of each period (which is equal to the bequest in the case of death), plus disposable income net of housing expenditures

\footnotetext{
${ }^{10}$ The aggregate average wage correlation with stocks will, therefore, also be large even at a high frequency. However, as described in the text, any individual household's wage contains idiosyncractic components that substantially reduce its own high frequency correlation with stock returns. Only wage-indexed factors and stock returns are highly correlated at low frequency for households.
} 
received before retirement, plus social security benefits (after retirement):

$$
X_{i, t}=W_{i, t}+\left(1-h_{t}\right) Y_{i, t}^{d}+S S_{i, t}
$$

Given the cash on hand at time $t$, individual $i$ then jointly decides how much to consume $C_{i, t}$ and the share of the residual savings, $X_{i, t}-C_{i, t}$, that is invested into risky equities versus risk-free bonds. Denote $\alpha_{i, t}$ as the proportion invested into the risky asset; hence, $\left(1-\alpha_{i, t}\right)$ is the share invested into risk-free bonds. We assume $\alpha_{i, t} \in[0,1]$, so that the allocation into bonds and stocks has to be non-negative during any period. ${ }^{11}$

For calibration purposes, we allow the investment return to be taxed at a rate $\tau_{d} . R_{i, t}$ denotes the total gross real return on the portfolio at time $t$. When the net stock return is positive $R_{i, t}^{S}>1$, the investor is taxed on both asset classes; otherwise, only the risk-free asset is taxed: ${ }^{12}$

$$
\begin{aligned}
R_{i, t} & =\left[\alpha_{i, t} \cdot R_{i, t}^{S}+\left(1-\alpha_{i, t}\right) \cdot R_{f}-1\right] \cdot\left(1-\tau_{d}\right)+1 \text { for } R_{i, t}^{S}>1 \\
& =\alpha_{i, t} \cdot R_{i, t}^{S}+\left(1-\alpha_{i, t}\right) \cdot\left[\left(R_{f}-1\right) \cdot\left(1-\tau_{d}\right)+1\right] \text { for } R_{i, t}^{S} \leq 1
\end{aligned}
$$

Putting these pieces together, the amount of wealth in the following period $t+1$ equals $^{13}$

$$
W_{i, t+1}=R_{i, t}\left(X_{i, t}-C_{i, t}\right)
$$

The model, therefore, has four state variables, $\left\{t, X_{i, t}, z_{i, t}, \bar{Y}_{i, t+1}\right\}$, along with two ageindexed control variables: $\left\{C_{i, t}, \alpha_{i, t}\right\}_{t=t_{0}}^{T} \cdot{ }^{14}$ Individual $i$ 's maximization problem can be

\footnotetext{
${ }^{11}$ A short position in equities $(\alpha<0)$ would expose agent $i$ to potentially unbounded losses, a risk that would never be taken under the Inada conditions implied by CRRA utility. However, a short position in bonds $(\alpha>1)$ is possible (with a low CRRA parameter $\gamma$ and a large enough equity premium $\eta$ ) provided that unemployement risk where zero $(\lambda=0)$ so there is some present value of "safe" future labor income.

${ }^{12}$ Thus, we take a conservative view on the value of the carry forward provisions in the tax law for loss offsets.

${ }^{13}$ In some simulation results not reported herein, we imposed the constraint that the total amount of saving invested into the risky asset $\alpha_{i, t}\left(X_{i, t}-C_{i, t}\right)$ exceed a minimum threshold $m$ in each period of life. This constraint is potentially relevant for households without access to employer-based defined-contribution plans. However, this constraint did not seem to materially impact our key results.

${ }^{14}$ Despite our choice of homothetic utility, our model is not homogenous of degree 1 due to the presence of nonlinear fiscal policies. We, therefore, cannot drop the current state of income. We must also track the household's average wage.
} 
restated recursively as follows

$V_{i, t}\left(X_{i, t}, z_{i, t}\right)=\max _{C_{i, t}, \alpha_{i, t}}\left\{\frac{\left(C_{i, t}\right)^{1-\gamma}}{1-\gamma}+\beta E_{t}\left[p_{t} \cdot V_{i, t+1}\left(X_{i, t+1}, z_{i, t+1}\right)+b\left(1-p_{t}\right) \cdot\left(\frac{\left(W_{i, t+1}\right)^{1-\gamma}}{1-\gamma}\right)\right]\right\}$

subject to ${ }^{15}$

$$
\begin{aligned}
& \alpha_{i, t} \in[0,1] \\
& X_{i, t+1}=R_{i, t}\left(X_{i, t}-C_{i, t}\right)+\left(1-h_{t+1}\right) Y_{i, t+1}^{d}+S S_{i, t}
\end{aligned}
$$

\subsection{Numerical Solution}

This maximization problem cannot be solved analytically. So numerical dynamic programming methods are used. We pay a considerable amount of attention to "implementation details" in order to ensure that our results produced small Euler errors away from boundaries (Appendix C), which is ultimately the best way to double-check the accuracy of the results.

The model is solved using backward iteration over the time (that is, age) dimension to derive the policy functions $C_{i, t}\left(X_{i, t}, z_{i, t}, \bar{Y}_{i, t+1}\right)$ and $\alpha_{i, t}\left(X_{i, t}, z_{i, t}, \bar{Y}_{i, t+1}\right)$.The continuous state space is approximated using a power-spaced discrete grid. The value of the function $V_{i, t+1}$ must be approximated between grid points across the three non-time dimensions: Schumaker shape-preserving quadratic splines are used for interpolating within the cash-onhand dimension while bilinear interpolation is inside the other two dimensions. ${ }^{16}$ There exist three labor income shocks $\left(\omega_{i, t}, \xi_{t}\right.$ and $\left.\phi_{i, t}\right)$ as well as uncertainty in excess stock returns $\eta_{t}$. Gauss-Hermite quadrature is used for the numerical integration to compute the expectations. However, since the innovations to stock returns are allowed to be correlated with an aggre-

\footnotetext{
${ }^{15}$ We also require that total savings at time $t$ be positive (i.e., $\left(X_{i, t}-C_{i, t}\right)>0$ ) to prevent any attempt to borrow against the "safe" portion of future labor income or social security benefits. To be sure, this constraint should also never bind for households before retirement under the Inada conditions. The reason is that, under our distributional assumptions, the individual $i$ 's labor income in any year could be zero, as could the aggregate wage index factor. (In other words, there is actually no positive levels of "safe" labor or social security income prior to retirement.) Of course, in actual simulations, both of these terms must be bounded above zero when using standard numerical integration methods. Hence, the constraint is enforced by making sure that the minimum integrated node is sufficiently small.

${ }^{16}$ We thanks Ken Judd for this suggestion. Consistent with suggestions in Judd (1998), we found several other approximation methods to be very inaccurate, including Chebyshev polynomials. Schumaker splines do not generalize easily to more than one dimension.
} 
gate permanent income shock, a transformation to the Gauss-Hermite quadrature is required in order to implement the bivariate normal distribution (Appendix B). Maximization at each grid point is performed using a combination of simplex optimization (Nelder-Mead) and Brent's method. While slower than gradient-based methods, they are more reliable. ${ }^{17}$

Correctly imposing the constraint (16) requires some care. The optimization problem is first solved (using simplex optimization) at the given grid point without the constraint (16) imposed. If the constraint (16) is not violated then that solution is obviously used. Otherwise, two additional conditional optimization problems are solved (now using Brent's method): where $\alpha_{i, t}=0$ and where $\alpha_{i, t}=1$. The best solution (highest value function) of those two optimizations is then chosen, which under our convexity assumptions, must be larger than any interior point where $0<\alpha_{i, t}<1$. Solving individual $i$ 's lifetime maximization problem, therefore, requires up to $600,000,000$ optimization subproblems to be solved. ${ }^{18}$ The simulation is solved with FORTRAN 90 MPI using a grid network with parallelizatio.

Following Judd (1992, 1998), the accuracy of any simulation is judged from the Euler equation errors produced by the approximation. Appendix $\mathrm{C}$ describes how we calculate the Euler errors for our model as a fraction of consumption, thereby giving a meaningful (scale independent) interpretation to the errors. Except at corner constraints (where the Euler equation does not hold), the optimizations are required to satisfy a small sup norm error.

\section{Calibration}

Our model is calibrated to the United States economy in 2004, prior to the rise of target date funds. We group individuals by their maximum amount of education obtained: $i \in$ \{“No High School”,"High School”, “College”\}. Specifically, individuals with "No High School” do not have a high school diploma; individuals with "High School” have a high school diploma but not college; individuals with “College” have obtained a college degree.

\footnotetext{
${ }^{17}$ Several other maximization methods and approaches were explored, including derivative-based methods as well as quasi-Newton methods that ensure a correctly signed inverse Hessian matrix. A high-end commerical package was also tested. However, none of them were either as accurate (based on Euler Equation errors) or even as as fast (due to many interations caused by instability) as the approaches that we eventually settled upon.

${ }^{18}$ We reject any simulation (and, hence, try another approach) if any of the subproblems fail to solve. Hence, we are forced to use methods that are very stable and perform well globally.
} 


\subsection{Preferences}

Individual $i$ without a college degree starts working at age 20 while individuals with a college degree begin working at age 22. All households retire at age 65 and can live up to age 100. The mortality data for the whole population follow the National Vital Statistics Reports from National Center for Health Statistics (Elizabeth Arias 2004). The benchmark bequest intensity parameter $b$ is set equal to 3 to help best calibrate the model.

\subsection{Asset Properties}

The riskfree return $R_{f}$ is set equal to $2.00 \%$ while the average equity premium $\mu$ is equal to $4.00 \%$ per year, close to their empirical averages. The standard deviation of the innovation to excess returns $\sigma_{\eta}$ is set equal to its historical value 0.157. ${ }^{19}$ Empirically, the correlation of stocks and individual $i$ 's wages at an annual frequency $\rho_{y \eta}$ is fairly small. The value of the correlation between the aggregate average wage and stock returns $\rho_{\xi \eta}$, however, is quite large at a low (30-year) frequency, although it is measured with considerable uncertainty. We use a point estimate of 0.80 as our benchmark parameter which is consistent with Jermann (1999) and with our own estimates.

\subsection{Labor Income and Housing Expenditures}

Our labor income process follows the careful empirical analysis of Cocco, Gomes and Maenhout (CGM) (2005), who used the Panel Study of Income Dynamics (PSID) to estimate the deterministic function of labor income $g\left(t, F_{i, t}\right)$, which they interpret broadly to include all of the sources of income listed in Appendix A. The variable $g\left(t, F_{i, t}\right)$ is assumed to be additively separable in $t$ and $F_{i, t}$ and a third-order polynomial that is estimated to fit the age-wage profiles. Like them, we adopt the variances of transitory shocks and permanent shocks on labor income from Carroll (1997). The unemployment probability is set to be $0.5 \%$, approximately equal to the percentage of zero income observations in CGM. The correlation coefficient between stock returns shocks and labor income shocks follows Campbell

\footnotetext{
${ }^{19}$ This value has been used in a couple previous papers; most of the literature uses a value between $0.15-0.20$.
} 
Table 1: Common Parameters in All Simulations

Description

Parameter Value

\begin{tabular}{lr}
\hline \hline Start working age $\left(t_{0}\right)$ & $20 / 22$ \\
Retirement age $(M)$ & 65 \\
Coefficient of relative risk aversion $(\gamma)$ & 5 \\
Riskless returns $\left(R_{f}\right)$ & 1.02 \\
Mean risky returns $\left(R_{f}+\mu\right)$ & 1.06 \\
Variance of transitory income shocks $\left(\sigma_{\omega}^{2}\right)$ & 0.01 \\
Variance of permanent income shocks $\left(\sigma_{u}^{2}\right)$ & 0.01 \\
Standard deviation of stock returns $\left(\sigma_{\eta}\right)$ & 0.157 \\
Correlation between stock returns and income shocks $\left(\rho_{\xi \eta}\right)$ & 0.8 \\
\hline Social security tax rate $\left(\tau_{S S}\right)$ & 0.124 \\
Investment return tax rate $\left(\tau_{S S}\right)$ & 0.20 \\
Bequest intensity $(b)$ & 3 \\
Unemployment probability $(\lambda)$ & $0.5 \%$ \\
Minimum income $(m)$ & $\$ 10,000$ \\
Marital status & single \\
Family size & 1
\end{tabular}

Table 2: Labor Income Process

Coefficient of characteristic variables for labor income No High School High School College

\begin{tabular}{lcrc} 
Constant & 2.6275 & 2.7004 & 2.3831 \\
Marital status & 0.4008 & 0.4437 & 0.4831 \\
Family size & -0.0176 & -0.0236 & \multicolumn{1}{c}{-0.0228} \\
\hline \hline Coefficient of age dummies for labor income & & & \\
\hline Constant & -2.1361 & -2.1700 & -4.3148 \\
Age & 0.1684 & 0.1682 & 0.3194 \\
Age $^{2} / 10$ & -0.0353 & -0.0323 & -0.0577 \\
Age $^{3} / 100$ & 0.0023 & 0.0020 & 0.0033
\end{tabular}

et al. (2001). ${ }^{20}$ We also impose a minimum income threshold of $\$ 10,000$ to model the safety net for poor people. ${ }^{21}$ The share of expenditures spent on housing $h_{t}$ is taken from Gomes and Michaelides (2005), which they estimate using PSID data between 1976 and 1993 as a function of age. Table 1 reports the key parameter values while Table 2 reports the income process coefficients by education grouping.

\footnotetext{
${ }^{20}$ Since the underlying data was in 1992 dollars while the fiscal policy part of our model is scaled to 2004 dollars, we use the change in the Consumer Price Index 34.11\% as the inflation rate from 1992 to 2004.

${ }^{21}$ This threshold is approximately equal to the 2004 US Department of Health \& Human services poverty threshold. See http://aspe.hhs.gov/poverty/04poverty.shtml
} 
Table 3: 2004 Progressive Federal Personal Income Tax Rates

\begin{tabular}{cc} 
Tax Rate & Single Filers \\
\hline \hline $10 \%$ & Up to $\$ 7,150$ \\
$15 \%$ & $\$ 7,151-\$ 29,050$ \\
$25 \%$ & $\$ 29,051-\$ 70,350$ \\
$28 \%$ & $\$ 70,351-\$ 146,750$ \\
$33 \%$ & $\$ 146,751-\$ 319,100$ \\
$35 \%$ & $\$ 319,101$ or more
\end{tabular}

\subsection{Progressive Federal Tax and Social Security Benefit Formula}

We adopt the 2004 federal personal income tax rates (shown in Table 3 for single filers). Taxes on both risky and riskless asset returns $\tau_{d}$ are set at proportional rate of $20 \%$.The social security tax rate $\tau_{S S}$ is $12.4 \%$. After calculating the AIYE, we calculate the annual social security benefit using the following three-region "bend point" formula used by the U.S. Social Security system in 2004: 90 percent of the first \$7,344 of AIYE, plus 32 percent of the AIYE over \$7,344 through 44,268, plus 15 percent of the AIYE above 44,268.

\section{Results for High School Education}

After obtaining the optimal policy functions for each grid point on the state, we generate an initial distribution of random variables for labor income shocks and portfolio return shocks then simulate over 10,000 households. This section reports the average (mean) outcomes by age for those individuals in the middle education group, namely, those people with a high school degree. We calibrate the value of $\beta=0.9$ so that the model generates a populationweighted average wealth-income ratio that is close to its empirical counterpart for the High School group. ${ }^{22}$

Figure 3 shows the average labor (plus social security) income and consumption profiles by age for the High School group. Average labor income takes the standard "hump shape" $(\cap)$ and drops to zero at retirement when Social Security benefits become positive. Consumption is also hump shaped, which is not standard in a deterministic lifecycle model where consumption should be monotonic in age. Intuitively, in the presence of income uncertainty

\footnotetext{
${ }^{22}$ Hence, we are not separately targeting the portfolio choice over the lifecycle. Moreoever, we are not able to control the wealth-income ratio over the entire lifecycle.
} 
Figure 3: Income and Consumption Profile for High School Group

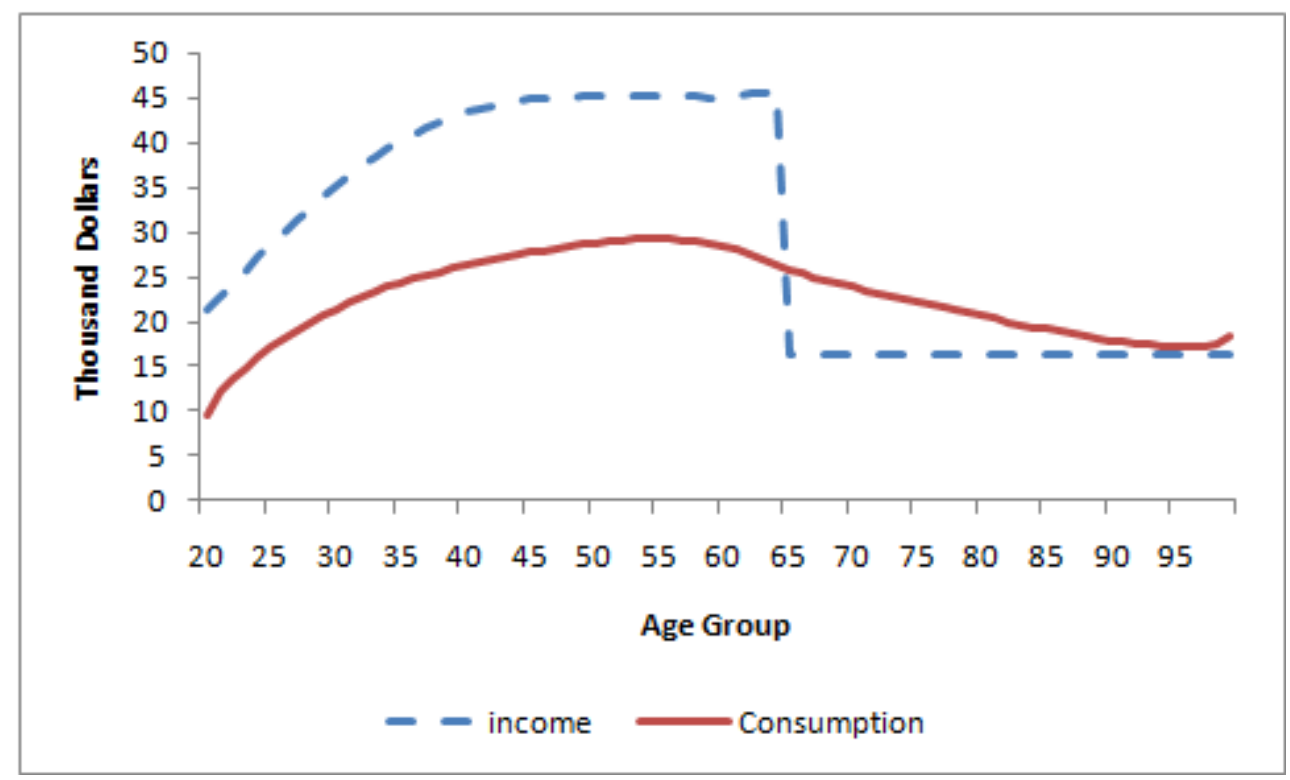

and CRRA utility (where the third derivative in consumption is positive), individuals save for precautionary reasons in addition to standard retirement reasons. Hump-shaped consumption profiles emerge as a combination of precautionary savings and impatience, producing an optimal consumption path that often closely tracks income (Zeldes 1989; Deaton 1991; Carroll 1992; Hubbard, Skinner and Zeldes 1994).

Figure 4 shows that the model's simulated wealth-income ratio appears to match the data quite closely over the lifecycle. One obvious exception is at the oldest age group where survivor bias might play a role in the data since wealthier households tend to live longer than poorer households. Our simulations do not attempt to correct for this wealth-longevity correlation. ${ }^{23}$

Figure 5 shows the share of financial assets allocated to stocks versus bonds for the benchmark case as well as the empirical allocation in the SCF from Figure 1. Notice that the simulated stock allocation is much less than $100 \%$ and fairly close to the actual empirical

\footnotetext{
${ }^{23}$ While allowing for a wealth-longevity correlation would not require an additional state variable, it is actually fairly complicated when $\gamma>1$, due to negative utility. In particular, longer longevity would actually reduce utility. In effect, allowing for longer longevity changes the preference parameters (the augmented utility weight) of an individual, making it difficult to compare.
} 
Figure 4: High School Group Wealth/Income Ratio

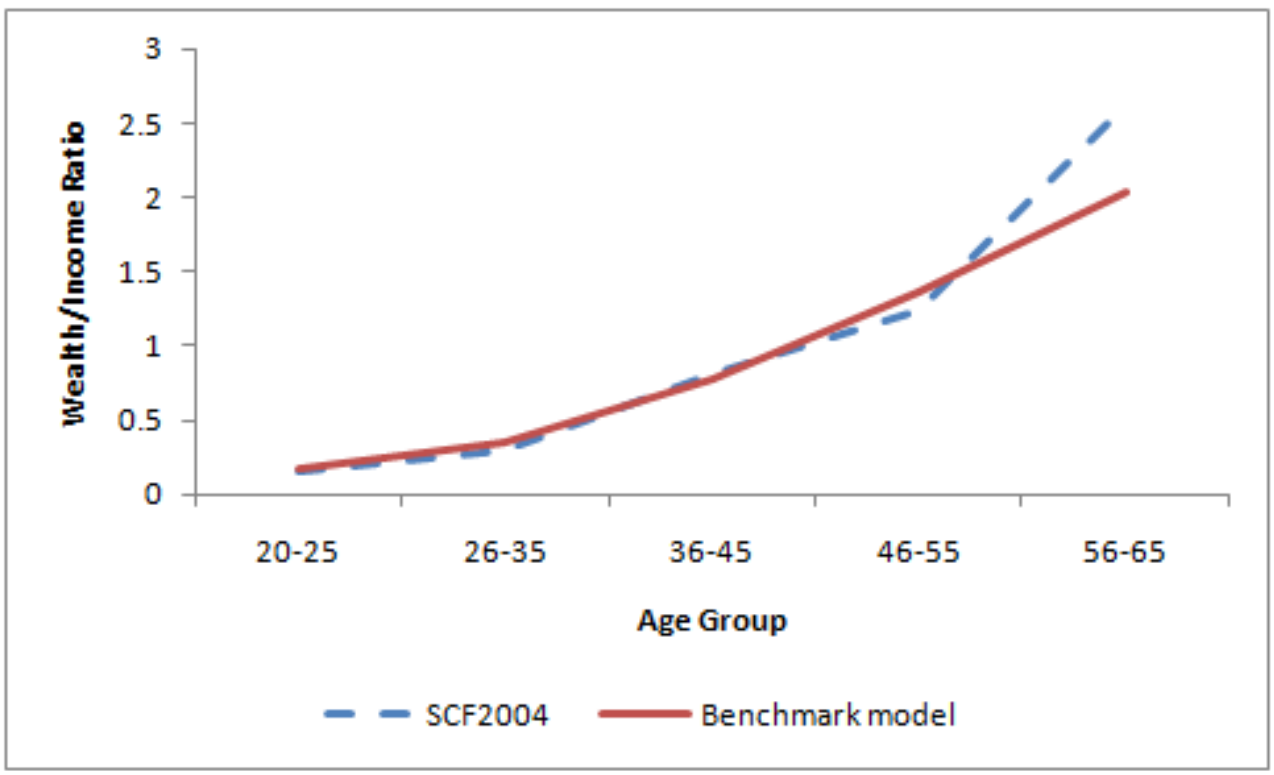

Figure 5: High School Group Stock Allocation

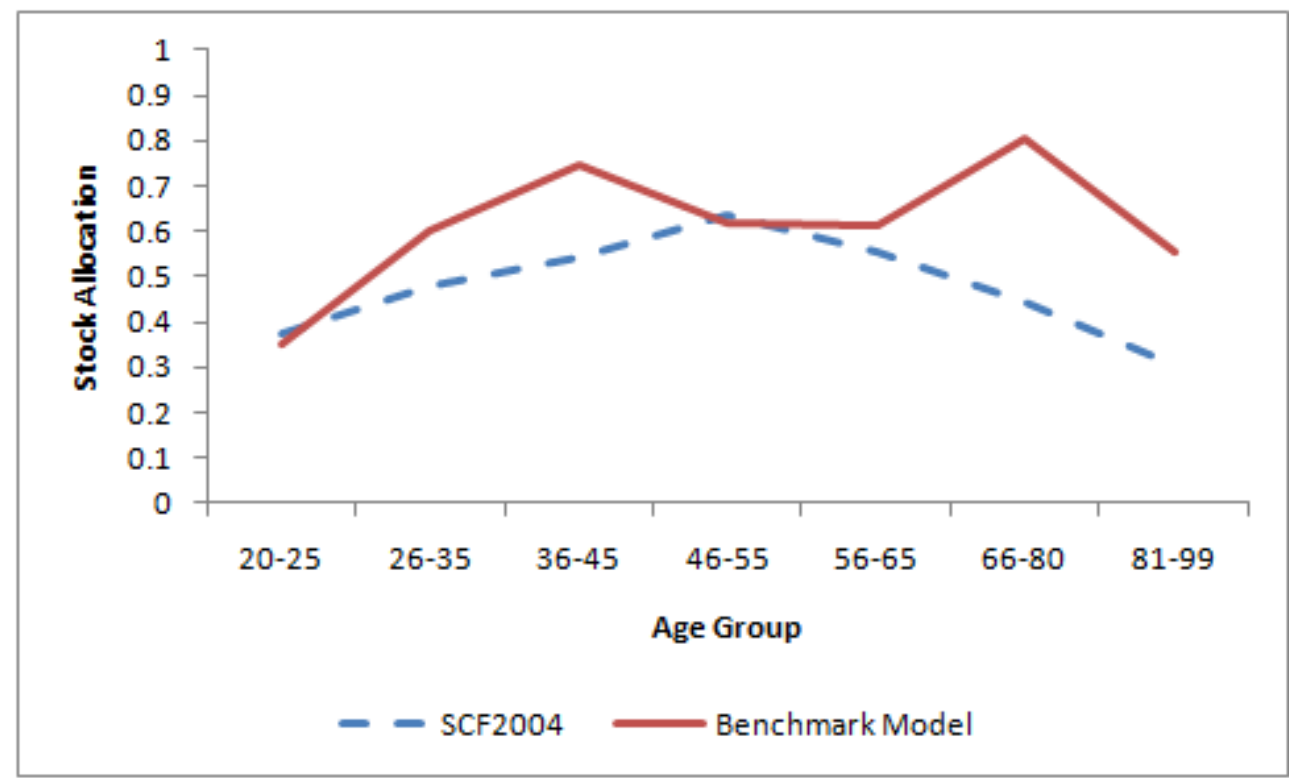


data. This result is in contrast to the traditional lifecycle model where the stock allocation is near $100 \%$ when young and decreases to about $60 \%$ nearer retirement. Moreover, the stock allocation profile in Figure 5 is fairly reasonable to the "hump shape" $(\cap)$ pattern observed in empirical data. Of course, the results are not a perfect fit by any means. Our model is clearly stylized and the data itself likely also contains a fair amount of "noise."

The hump shape is produced by the model in presence of several competing factors that vary by age. First, risky stocks and social security are highly substitutable during young ages where aggregate wage-indexed social security benefits are still quite uncertain. However, as a person ages, bonds and social security become more substitutable over time as social security benefits accrue and the potential risk in the wage-indexed factor is reduced. The net effect is to cause the allocation in stocks to start relatively low at a young age and then increase in age. Second, similar to previous models, agent $i$ 's specific human capital depreciates over the lifecycle. Since stock returns and individual wages are not highly correlated, this effect produces a larger stock allocation in middle age that then decreases with additional age. Third, the background risk caused by non-insurability of human capital returns interacting with the utility function's Inada condition diminishes over the lifecycle, which can increase the share allocated toward risky stocks. Putting these competing factors together produces a "hump” shaped stock allocation.

In fact, a "second hump" (creating a "M” like pattern) also emerges as households retire. After retirement - that is, once the initial benefit amount is calculated - Social Security benefits are not adjusted for wage growth and only keep pace with inflation. As households retire and the Social Security benefit is safe, households with longer horizons (more weight on future utility) will shift their allocation again toward stocks.

\section{College and No High School}

We also calibrated our model for the College and No High School groups by targetting the empirical population-weighted average wealth-income ratios for the respective education group. The resulting value of $\beta$ is equal to 0.95 for the College group and 0.8 for No High School group. (Recall that $\beta=0.9$ for the baseline High School group considered earlier.) Notice that the required calibrated value of $\beta$ increases with education level, which 
Figure 6: College Group Wealth/Income Ratio

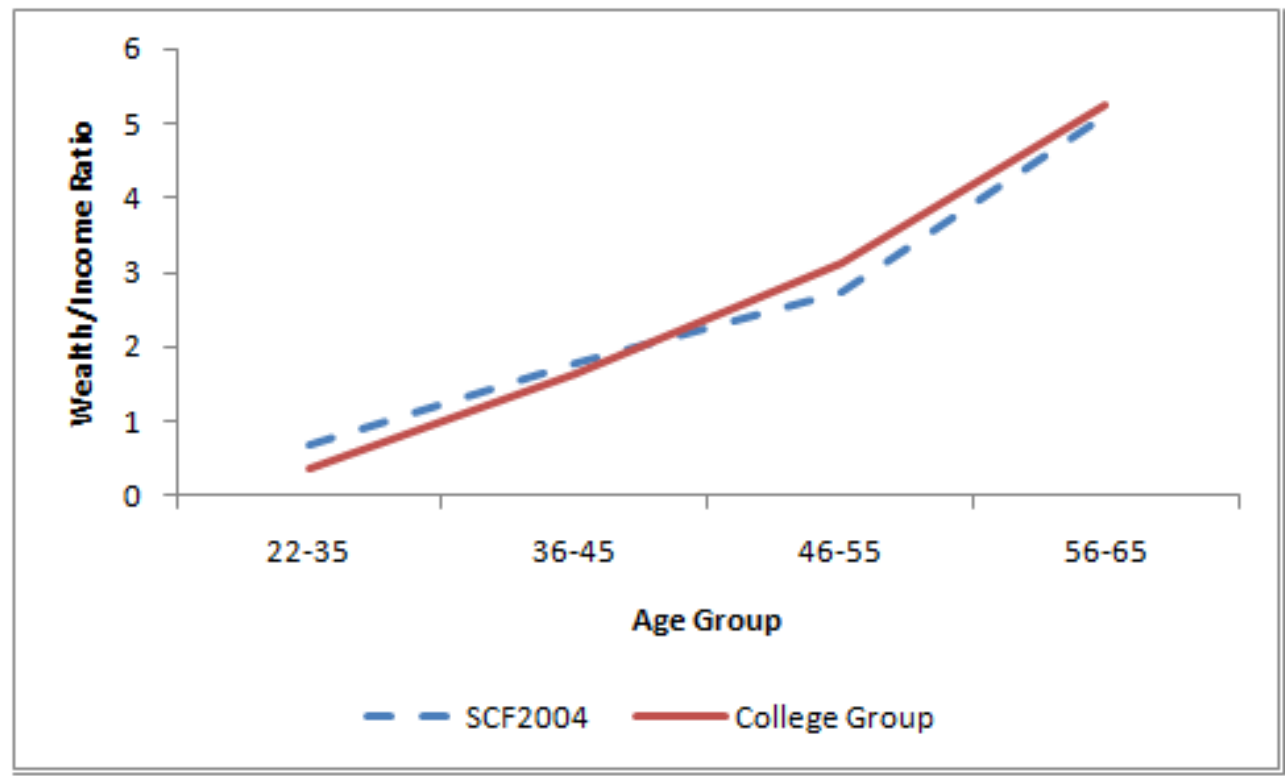

Figure 7: College Group Stock Allocation

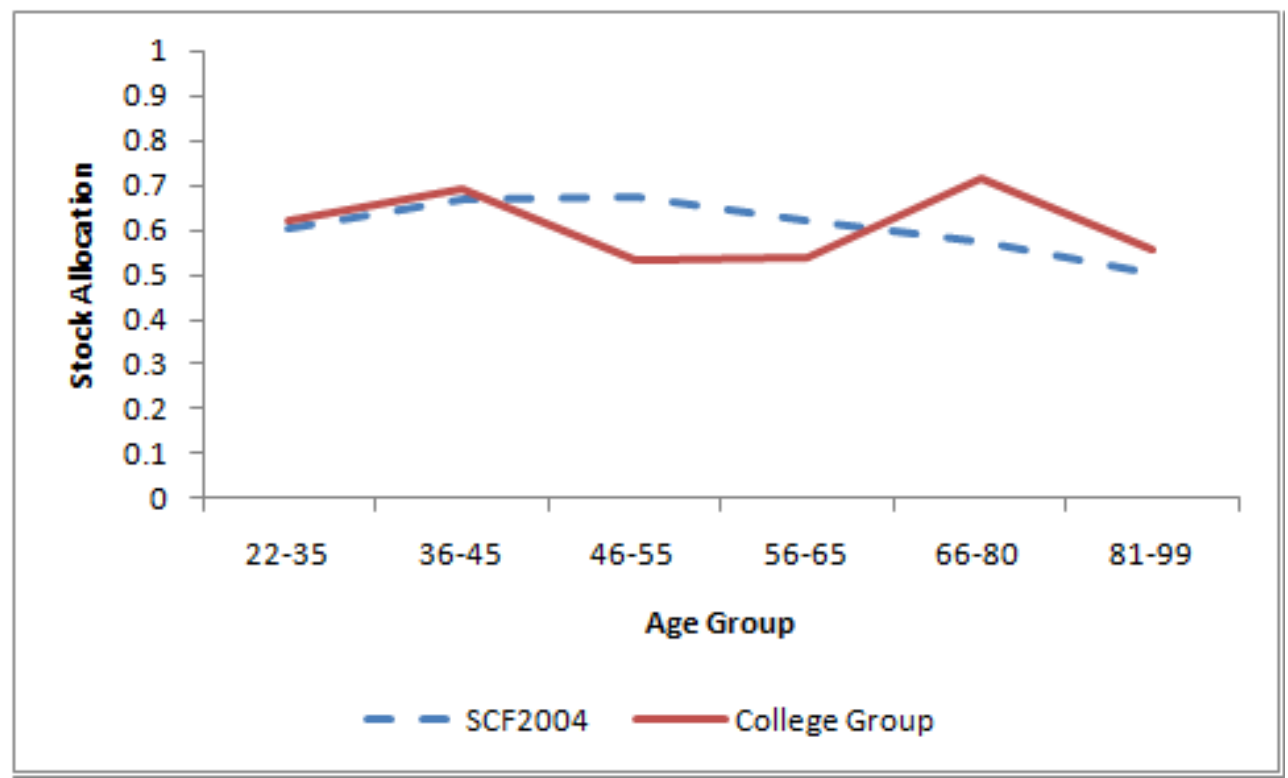


Figure 8: No High School Group Wealth/Income Ratio

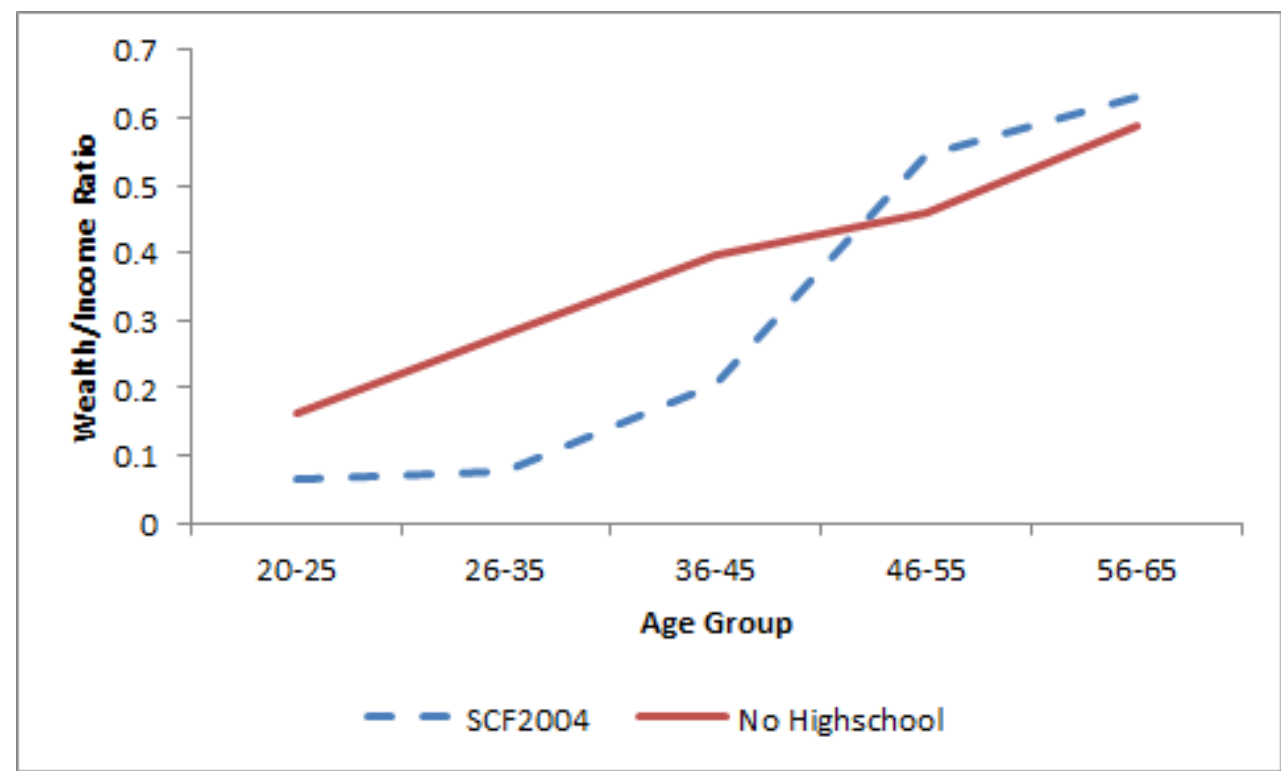

Figure 9: No High School Group Stock Allocation

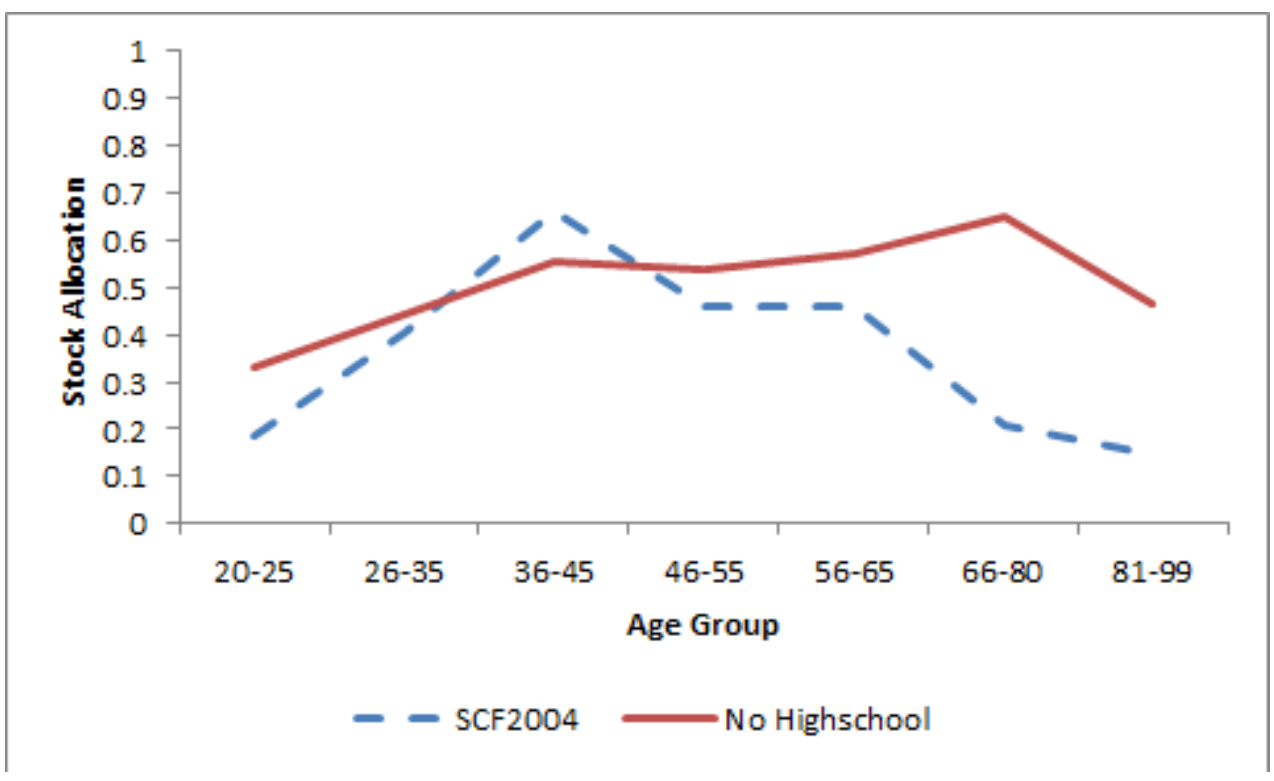


is intuitive because the education decision likely reflects their time preferences. People who choose to invest in more education are likely to be relatively more patient.

Figures 6 and 8 show the corresponding lifecycle wealth-income ratios for each education group, compared with the empirical counterpart. Figure 7 and 9 show the stock allocation for College group and the No High School group, respectively. The stock allocation pattern produced by the model for households with College eduction (Figures 7) is similar to the benchmark High School group considered earlier. One key exception is that College educated households hold relative more equities at younger ages, which produces a smoother portoflio over the lifecycle. Intuitively, the progressive nature of Social Security benefits in our model implies that wage indexation is relatively less important for College educated households. As a result, a College educated household invests a greater fraction of their assets into equities at a younger age relative to the High School group (i.e., our model is not homogenous of degree 1). Consistently, the poorest No High School group hold fewer equities (Figure 9).

\section{Sensitivity Analysis}

\subsection{Low correlation between aggregate average wage and stock returns}

To explore the importance of the role of wage-indexed Social Security, Figure 10 shows the stock allocation of the benchmark High School group when the correlation between the aggregate average wage and stock returns is smaller $\left(\rho_{\xi \eta}=0.15\right)$. The results are similar to those found in previous papers. The stock allocation starts near $100 \%$ for younger households and declines over time. Reducing the correlation between the aggregate average wage and stock returns makes social security less correlated with stocks, therefore significantly increasing the demand for stocks.

\subsection{Risk aversion}

We now also show the results for the High School group with a lower risk aversion $(\gamma=3)$ and with a higher risk aversion $(\gamma=7)$. In order to rematch the empirical average wealthincome ratio, the beta is recalibrated accordingly ( 0.95 for $\gamma=3$ and 0.8 for $\gamma=7$ ).

Figure 11 shows the stock allocation when risk aversion is low $(\gamma=3)$. Since households are less risk averse relative to the baseline, their stock allocation is relatively larger and close 
Figure 10: Stock Allocation with Low Correlation

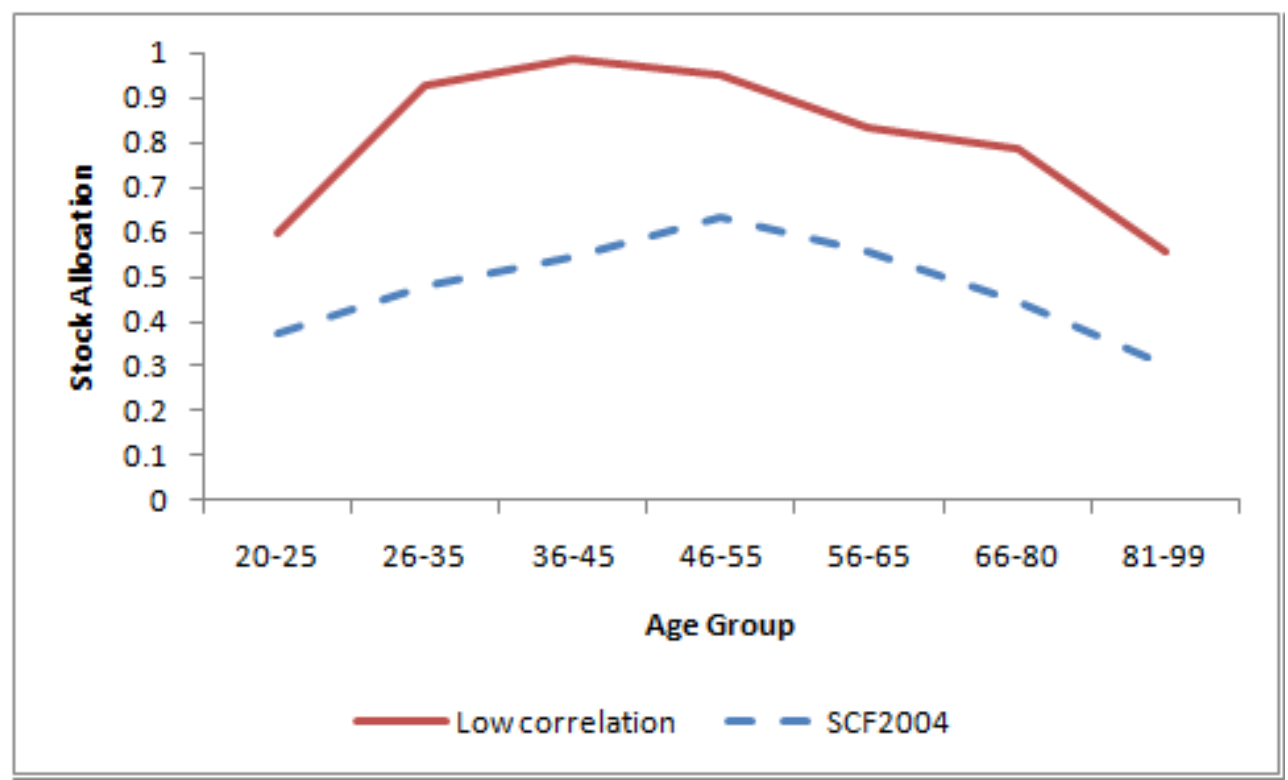

to $100 \%$ throughout the entire lifecycle. Figure 12 shows the stock allocation when risk aversion is large $(\gamma=7)$. Now, the stock allocation is much lower than the benchmark and the empirical data.

\section{Target Date Funds}

"Target date" (or "lifecycle”) funds have grown enormously during the past five years in the United States. ${ }^{24}$ A given target date fund targets a given retirement date (e.g., 2035) and automatically rebalance the stock-bond allocation over time toward more bonds as the targeted retirement date is approached. Their main purpose is to essentially simplify the portfolio allocation process along the lines that is consistent with the traditional financial advice, thereby reducing "mistakes.” The Pension Protection Act of 2006 increased the popularity of target date funds by allowing employers to make them the "default option” in their 401(k) plans without fear of liability. ${ }^{25}$ Of the 380 target-date funds currently in existence, more than 300

\footnotetext{
${ }^{24}$ The SCF data presented herein corresponds to a period before the popularity of target date funds.

${ }^{25}$ To encourage savings by less affluent households, the Pension Protection Act of 2006 allows for automatic (“opt out”) enrollment, which is especially important for less affluent households who do not make active decisions. Plan sponsors (employers) are protected from liability associated with potential future losses in fund value
} 
Figure 11: Stock Allocation with Low Risk Aversion

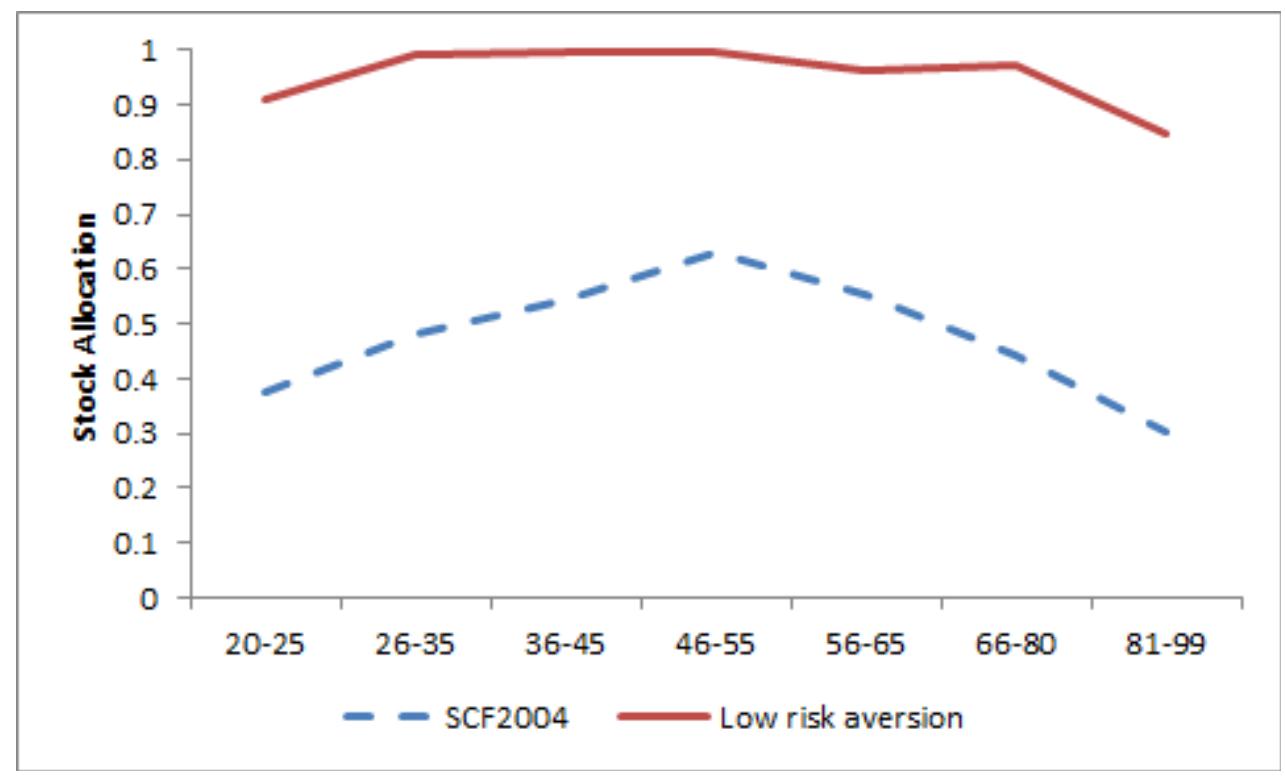

Figure 12: Stock Allocation with High Risk Aversion

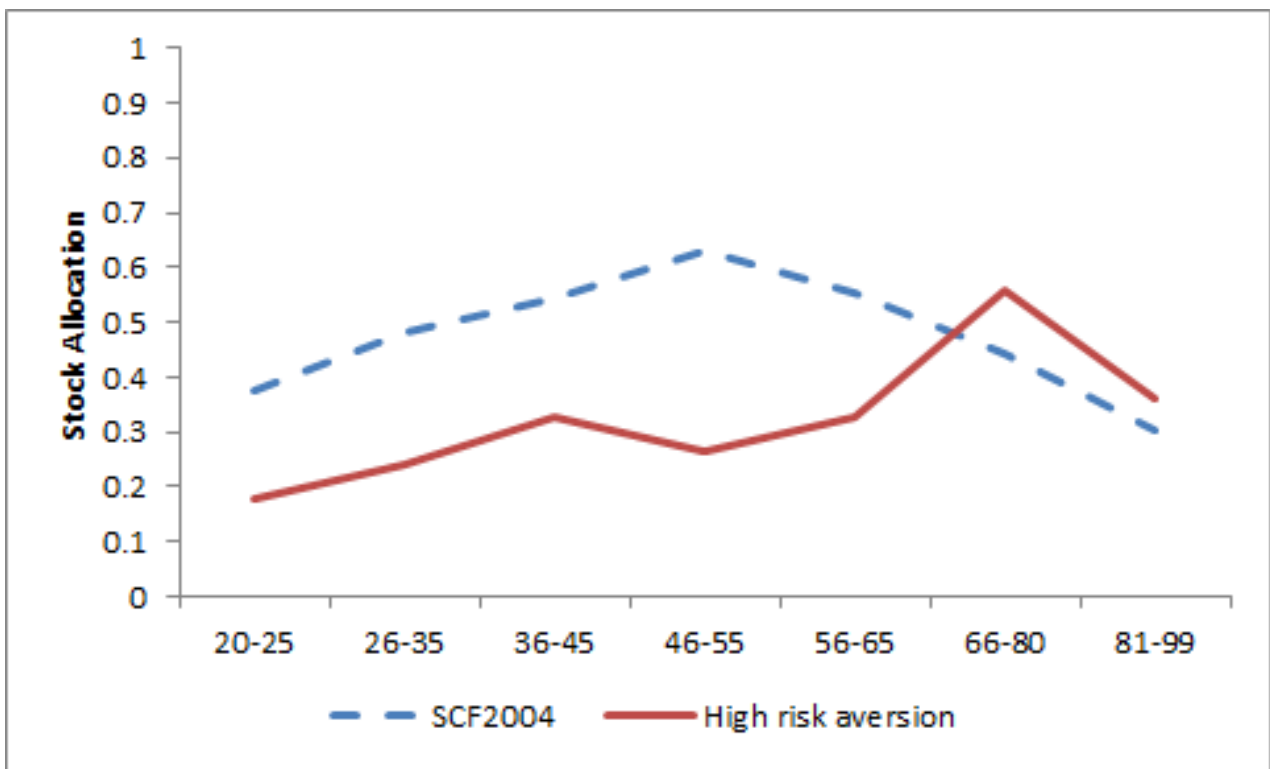


Figure 13: Model Generated Stock Allocation vs. Data and Target Date Fund

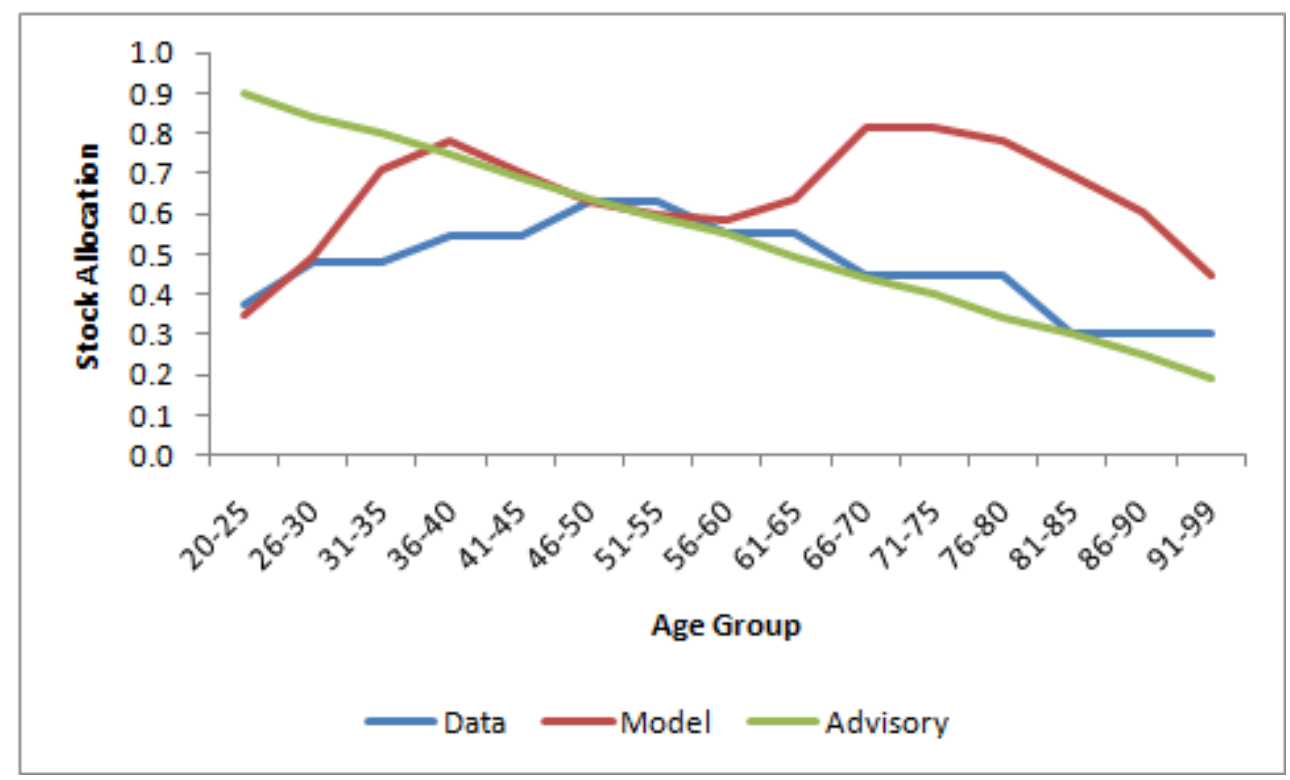

are less than six years old and have originated after the 2004 SCF data was collected. ${ }^{26}$

Of course, relative to our model, any lifecycle allocation rule would, by definition, produce a lower level of welfare than the age-based allocation produced by our model itself. So, we instead ask a more meaningful question: do target date funds actually produce a higher level of welfare relative to what households were achieving on their own before they these funds were introduced? In other words, do target date funds potentially introduce more mistakes than what households were already making?

Figure 13 shows the lifecycle stock allocation corresponding to a standard target date fund ("Advisory”), which starts at $90 \%$ and declines over time to about $20 \%$ by age 99 . This allocation is informally recommended by the U.S. Securities and Exchange Commission. ${ }^{27}$ It is also very similar to allocations offered by commercial providers. For comparison, Figure 13 also shows the actual empirical allocation for our baseline "High School" education class (“Data”) as well as our model generated allocation ("Model”).

if they follow the safe harbor guidelines of a Qualified Default Investment Account (QDIA). Target date funds are an acceptable and popular QDIA choice.

${ }^{26} \mathrm{http} / / /$ money.cnn.com/2009/04/27/news/companies/kimes_targetfunds.fortune/index.htm?postversion=2009042713

${ }^{27}$ http://www.sec.gov/investor/pubs/assetallocation.htm 
Notice that above age 55, the Advisory allocation already closely tracks the Data allocation pretty well. As a result, a target date fund provides very little opportunity to improve welfare for older households relative to their existing behavior; indeed, older households with more assets are already likely to be aware of the traditional advice that underlies the target date funds. For households between age 35 and 50, the Advisory allocation traces the optimal Model allocation fairly well, indicating that the target date fund may provide optimal recommendation. However, for household before age 35, the Model allocation is generally closer to the Data allocation relative to the Advisory allocation. This fact suggests that the adoption of a target date fund could be welfare decreasing; households might be better off with their current allocations. Overall, the effect on lifetime utility, therefore, is ambiguous and needs formal measurement.

To measure the change in welfare from adopting a target date fund, we solve a constrained version of our model where the asset allocation is taken as exogenous. The constrained optimal solution is calculated under the Advisory allocation. The constrained optimal solution is also calculated under the Data allocation shown in Figure 13. In each case, households are allowed to reoptimize their lifetime savings decision under the given sttockbond allocation.

Let $\Omega=\int_{X} \int_{z} V_{i, 20}\left(X_{i, 20}, z_{i, 20}\right) \mathrm{d} X_{20} \mathrm{~d} z_{20}$ denote the ex-ante expected utility at age 20 across the different sources of uncertainty upon entering age 20. The corresponding compensating variation (welfare change) associated with adopting the target date fund at age 20 is then defined as $\left[\frac{\Omega^{\text {Advisory }}}{\Omega^{\text {Data }}}\right]^{\frac{1}{1-\gamma}}-1$, where $\Omega^{\text {Advisory }}$ and $\Omega^{\text {Data }}$ are the expected utilities from the Advisory and Data allocations, respectively. A positive compensating variation indicates a welfare gain from adopting the target date allocation, while a negative compensating variation indicates a welfare loss.

The compensating variation for the College group and No High School group are both negative (at $-0.2 \%$ and $-0.3 \%$ respectively), indicating a small welfare loss from adopting the target date fund. The compensating variation for the High School education group, though, is positive (about 1.4\%), indicating a small welfare gain from adopting the target date fund. These losses grow (and the positive gain turns negative) at higher level of risk aversion, which, incidentially, is consistent with the literature examining the equity premium puzzle. 
It is, therefore, unclear that the recent government policy encouraging the adoptation of target funds actually improves welfare. Of course, more work on this issue is needed. To the extent that target date funds move people to save and invest in the first place, they could be welfare improving. However, to the extent that an otherwise participating household believes that a target date fund was created by experts and provides a better allocation, investing in the target date fund could be welfare decreasing. Future analysis should consider these counterfactual scenarios at the household level in more detail.

\section{Conclusion}

Social security benefits are the largest asset for a majority of U.S. households. This paper examines how households should optimally allocate their portfolio choices between stocks and bonds when we recognize that this large unchosen benefit is progressive and wage indexed. The household decision rules are fundamentally altered. Empirically, households appear to be doing quite well and make only small "mistakes" at reasonable parameter values. Recent government attempts to simplify the investment process could very well leave many households worse off. 


\section{References}

[1] Ameriks, John, Zeldes, Stephen (2000). How do household portfolio shares vary with age? Unpublished manuscript. Columbia University.

[2] Ayers, Ian and Barry Nalebuff (2008). "Life-Cycle Investing and Leverage: Buying Stock on Margin Can Reduce Retirement Risk.” Working Paper, Yale Law School.

[3] Attanasio, Orazio, (1995). “The Intertemporal Allocation of Consumption: Theory and Evidence,” Carnegie-Rochester Conference Series on Public Policy, 39-89

[4] Balduzzi, Perluigi, and Anthony Lynch, (1997). "The impact of Predictability and Transaction Costs on Portfolio Choice in a Multiperiod Setting,” Working Paper, Boston College and New York University

[5] Benzoni, Luca, Pierre Collin-Dufresne, and Goldstein S. Robert (2004). "Portfolio Choice over the Life-Cycle in the presence of ‘Trickle Down’ Labor Income,” Working Paper

[6] Bertaut, Carol C. and Michael Haliassos, (1997). "Precautionary Portfolio Behavior from a Life Cycle Perspective,” Journal of Economic Dynamics and Control, 21, 15111542

[7] Bodie, Zvi; Robert C Merton; William F Samuelson (1992). "Labor Supply Flexibility and Portfolio Choice in a Life Cycle Model.” Journal of Economic Dynamics and Control, vol. 16, no. 3-4: 427-49

[8] Bodie, Z., J. Detemple, S. Otruba and S. Walter (2004). "Optimal ConsumptionPortfolio Choices and Retirement Planning,” Journal of Economic Dynamics and Control, 28.

[9] Brennan, Michael J. and Y. Xia, (1998). “Resolution of a Financial Puzzle,” Working Paper, Anderson Graduate School of Management, UCLA

[10] Brown, D.P. (1990). “Age clienteles induced by liquidity constraints.” International Economic Review 31, 891-911.

[11] Campbell, John Y., Joao F. Cocco, Francisco J. Gomes, and Pascal J. Maenhout, (2001). “Investing Retirement Wealth: A Life-Cycle Model”, Risk Aspects of Social Security Reform, University of Chicago Press

[12] Campbell, John Y. and John H. Cochrane, (1999). "By Force of Habit: A ConsumptionBased Explanation of Aggregate Stock Market Behavior," Journal of Political Economy, 107, 205-251

[13] Campbell, John Y. and Luis M. Viceira, (1999). "Consumption and Portfolio Decisions When Expected Returns are Time Varying," Quarterly Journal of Economics, May 1999, 433-496 
[14] Carroll, Christopher. D., (1992). "The Buffer Stock Theory of Saving: Some Macroeconomic Evidence,” Brookings Papers on Economic Activity, 2, 61-135

[15] Carroll, Christopher. D., (1997). "Buffer-Stock Saving and the Life-Cycle/Permanent Income Hypothesis,” Quarterly Journal of Economics, 112, 1-55

[16] Carroll, Christopher. D., (2002). "Portfolio of the rich, in Luigi Guiso, Michael Haliassos, and Tullio Jappelli, eds," Household Portfolios, MIT Press, Cambridge, MA

[17] Carroll, Christopher. D., and A. A. Samwick, (1997). "The Nature of Precautionary Wealth,” Journal of Monetary Economics, 40, 41-71.

[18] Cocco, Joao F., (1998). "Owner-Occupied Housing, Permanent Income, and Portfolio Choice”, working paper, Harvard University

[19] Cocco, Joao F., Francisco J. Gomes, and Pascal J. Maenhout, (1998), “Consumption and Portfolio Choice over the Life Cycle,” The Review of Financial Studies, Vol. 18, No. 2

[20] Davis, S., and W. Paul (2000). “Occupation-Level Income Shocks and Asset Returns: Their Covariance and Implication for Portfolio Choice,” NBER Working Paper 7905.

[21] Deaton, A. (1991). “Saving and Liquidity Constraints,” Econometrica, 59, 1121-1142

[22] Elizabeth Arias, (2004). “United States Life Tables,” National Vital Statistics Reports, Vol. 53, No. 6, November 10, 2004

[23] Faig, M., and P. Shum (2002). "Portfolio Choice in the Presence of Personal Illiquid Projects,” Journal of Finance. 57(1), 303-328.

[24] Gakidis, Haralabos (1998). "Portfolio Choice with Uninsurable Labor Earnings.” Massachusetts Institute of Technology, Mimeo.

[25] Gomes, Francisco, and Alexander Michaelides (2005), "Optimal Life-Cycle Asset Allocation: Understanding the Empirical Evidence," The Journal of Finance, April 2005, 869-904

[26] Gourinchas, P. O., and J. Parker (2002), “Consumption Over the Life Cycle,” Econometrica, 70, 47-91

[27] Gourinchas, Pierre-Olivier and Jonathan Parker (1996), "Consumption Over the Life Cycle,” working paper, MIT

[28] Heaton, John and Deborah J. Lucas (1997), "Market Frictions, Saving Behavior and Portfolio Choice,” Macroeconomic Dynamics, 1, 76-101

[29] Horneff, Wolfram, Raimond Maurer, Olivia Mitchell, Michael Stamos (2009), “Asset allocation and location over the life cycle with investment-linked survival-contingent payouts.” Journal of Banking and Finance 33: 1688 - 1699. 
[30] Hubbard, Glenn, Jonathan S. Skinner and Stephen Zeldes, (1994), "Precautionary Saving and Social Insurance,” Journal of Political Economy, 103, 360-399

[31] Jagannathan, R., and N. R. Kocherlakota, (1996), "Why Should Older People Invest Less in Stocks Than Younger People?” Federal Reserve Bank of Minneapolis Quarterly Review, 20, 11-23

[32] Jermann, Urban (1999). "Social Security and Institutions for Intergenerational, Intragenerational and International Risk Sharing: A Comment,” Carnegie-Rochester Conference Series on Public Policy: 205-212

[33] Judd, Kenneth L (1992). "Projection Methods for Solving Aggregate Growth Models." Journal of Economic Theory, 58: 410-452.

[34] Judd, Kenneth L., (1998). "Numerical Methods in Economics” MIT Press.

[35] Kim, Tong Suk, and Edward Omberg, (1996). "Dynamic Nonmyopic Portfolio Behavior,” Review of Financial Studies, 9, 141-161

[36] Merton, Robert C., (1969). "Lifetime Portfolio Selection under Uncertainty: The Continuous-Time Case,” Review of Economics and Statistics, 51, 247-257

[37] Merton, Robert C., (1971). "Optimum Consumption and Portfolio Rules in a Continuous-Time Model,” Journal of Economic Theory, 3, 373-413

[38] Samuelson, Paul A., (1969). "Lifetime Portfolio Selection by Dynamic Stochastic Programming,” Review of Economics and Statistics, 51, 239-246

[39] Social Security Administration, Office of Policy (2002). Income of the Aged Chartbook, 2002.

[40] Storesletten, Kjetil, Chris I. Telmer, and Amir Yaron, (2000). "Asset Pricing with Idiosyncratic Risk and Overlapping Generations,” Working Paper, Carnegie Mellon University

[41] Viceira, Luis M., (2001). “Optimal Portfolio Choice for Long Horizon Investors with Nontradable Labor Income,” Journal of Finance, 55, 1163-1198

[42] Zeldes, S. P. (1989). “Optimal Consumption with Stochastic Income: Deviations from Certainty Equivalence,” Quarterly Journal of Economics, 104, 275-298 


\section{Appendix A}

To construct the the household income, we include wages and salaries (X5702), practice/business/partnership/farm income (X5704), rent/trusts/royolties (X5714), unemployment or worker's compensation (X5716), child support or alimony (X5718), food stamps and welfare income (X5720) and other income (X5724).

Bonds and stocks are constructed as follows. All the acronym-variables are defined in the SAS program supplied by the SCF, which creates summary variables for SCF. Bonds consist of SAVING and MMA (savings and money market accounts), CDS (cerfiticates of deposit), TFBMUTF (tax free bond mutual funds), GBMUTF (government bond mutual funds), OBMUTF (other bond mutual funds), BOND (state, US government and corporate bonds), SAVBND (saving bonds) and COMUTF (combination and other mutual funds), for which we assume that half is invested to bonds. We also add ANNUIT (annuities) and TRUSTS (trusts), for which we count the full value if the individuals invest all in interest earning assets, while the percentage other than stock allocation if the individuals split the investment. Other bond investment includes bonds in IRA/KEOGH plans, bonds in accounttype retirement plans and FUTPEN (other future pension benefits). We also subtract CCBAL (revolving credit card debt), OTHLOC (unsecured loans and loans secured by pensions) and other debt, which includes loans against pensions (X11027, X11127, X11327, X11427, X11527), loans against life insurance (X4010) and loans against margin loans (X3932).

Stocks are made up of STOCKS (directly held stocks), STMUTF (stock mutual funds), half of COMUTF (combination and other mutual funds), OMUTF (other non-bond mutual funds), PENEQ (thrift amounts invested in stock), ANNUIT (annuities) and TRUSTS (trusts) that are invested in stocks. Other stock investment includes stocks in IRA/KEOGH plans, stocks in account-type retirement plans and FUTPEN (other future pension benefits).

The total financial wealth is defined as the total of bonds, stocks, CHECKING (checking accounts) and CALL (call accounts). 


\section{Appendix B}

$f(\cdot)$ denotes the p.d.f. of the variables. $I, J, K, L$ are the numbers of interpolation nodes for labor income shocks and stock returns shocks $\eta, \xi, \omega, \phi$, respectively. The distributions of the shocks are summarized as,

$$
\begin{aligned}
& \omega \stackrel{d}{\longrightarrow} N\left(\mu_{\omega}, \sigma_{\omega}^{2}\right) \\
& \phi \stackrel{d}{\longrightarrow} N\left(\mu_{\phi}, \sigma_{\phi}^{2}\right) \\
& \left(\begin{array}{l}
\eta \\
\xi
\end{array}\right) \stackrel{d}{\longrightarrow} N\left(\begin{array}{ccc}
\mu_{\eta} & \sigma_{\eta}^{2} & \rho_{\xi \eta} \sigma_{\xi} \sigma_{\eta} \\
\mu_{\xi} & \rho_{\xi \eta} \sigma_{\xi} \sigma_{\eta} & \sigma_{\xi}^{2}
\end{array}\right)
\end{aligned}
$$

For each individual $i$, at any time $t$ and any state point $\left(X_{i, t}, z_{i, t}\right)$, the expectation of the value function can be expressed as follows.

$$
\begin{aligned}
E_{\xi \eta \omega \phi} V_{t}\left(\xi, \eta, \omega, \phi, X_{t}, z_{t}\right) & =\int_{-\infty}^{\infty} \int_{-\infty}^{\infty} \int_{-\infty}^{\infty} \int_{-\infty}^{\infty} V_{t}\left(\xi, \eta, \omega, \phi, X_{t}, z_{t}\right) f(\xi, \eta, \omega, \phi) d \xi d \eta d \omega d \phi \\
& =\int_{-\infty}^{\infty} \int_{-\infty}^{\infty} \int_{-\infty}^{\infty} \int_{-\infty}^{\infty} V_{t}\left(\xi, \eta, \omega, \phi, X_{t}, z_{t}\right) f(\eta \mid \xi) d \eta \cdot f(\xi) d \xi \cdot f(\omega) d \omega \cdot f(\phi) d \phi
\end{aligned}
$$

For the bivariate normal distribution, the conditional distribution for one of the variables, given the value for the other variable, is normally distributed. Therefore,

$$
\eta \mid \xi \stackrel{d}{\longrightarrow} N\left(\mu_{\eta \mid \xi}, \sigma_{\eta \mid \xi}^{2}\right)
$$

where

$$
\begin{aligned}
& \mu_{\eta \mid \xi}=\mu_{\eta}+\frac{\rho_{\xi \eta} \sigma_{\eta}}{\sigma_{\xi}}\left(\xi-\mu_{\xi}\right) \\
& \sigma_{\eta \mid \xi}^{2}=\sigma_{\eta}^{2}\left(1-\rho_{\xi \eta}^{2}\right)
\end{aligned}
$$

Following P.262 of Kenneth Judd, if a normal random variable $X$ is distributed $N\left(\mu, \sigma^{2}\right)$, then the general Gauss-Hermite quadrature rule for expectation of $X$ is as follows, 


$$
E(X)=\pi^{-1 / 2} \sum_{i=1}^{n} w_{i} \cdot\left(\sqrt{2} \sigma x_{i}+\mu\right)
$$

where $w_{i}$ are the Gauss-Hermite quadrature weights, and $x_{i}$ are the quadrature nodes, $i=1,2, \ldots, n$.

So, the functional approximation of Gauss-Hermite quadrature to $\eta$ is

$$
\begin{aligned}
E_{\xi \eta \omega \phi} V_{t}\left(\xi, \eta, \omega, \phi, X_{t}, z_{t}\right) & =\pi^{-\frac{1}{2}} \int_{-\infty}^{\infty} \int_{-\infty}^{\infty} \int_{-\infty}^{\infty} \sum_{i=1}^{I} w_{i, \eta} V_{t}\left(\xi, \sqrt{2} \sigma_{\eta \mid \xi}+\mu_{\eta \mid \xi}, \omega, \phi, X_{t}, z_{t}\right) \\
& =\pi^{-\frac{1}{2}} \int_{-\infty}^{\infty} \int_{-\infty}^{\infty} \int_{-\infty}^{\infty} \sum_{i=1}^{I} w_{i, \eta} V_{t}\left(\xi, \sqrt{2} \sigma_{\eta} \sqrt{1-\rho_{\xi \eta}^{2}} \eta_{i}+\mu_{\eta}+\right. \\
\frac{\rho_{\xi \eta} \sigma_{\eta}}{\sigma_{\xi}} & \left.\left(\xi-\mu_{\xi}\right), \omega, \phi, X_{t}, z_{t}\right) \cdot f(\xi) d \xi \cdot f(\omega) d \omega \cdot f(\phi) d \phi
\end{aligned}
$$

where $w_{i, \eta}$ is the weights, $\eta_{i}$ is the nodes over $[-\infty, \infty]$.The procedure of discretizing $\xi$ is to substitute $\sqrt{2} \sigma_{\xi} \xi_{j}+\mu_{\xi}$ for $\xi$, which yields the following,

$$
\begin{aligned}
& E_{\xi \eta \omega \phi} V_{t}\left(\xi, \eta, \omega, \phi, X_{t}, z_{t}\right) \\
= & \pi^{-1} \int_{-\infty}^{\infty} \int_{-\infty}^{\infty} \sum_{j=1}^{J} \sum_{i=1}^{I} w_{i, \eta} w_{j, \xi} V_{t}\left(\sqrt{2} \sigma_{\eta}\left(\sqrt{1-\rho_{\xi \eta}^{2}} \eta_{j}+\rho_{\xi \eta} \xi_{j}\right)+\mu_{\eta}, \omega, \phi, X_{t}, z_{t}\right) \cdot f(\omega) d \omega \cdot f(\phi) d \phi
\end{aligned}
$$

Again $w_{j, \xi}$ and $\xi_{j}$ are the Gauss-Hermite quadrature weights and nodes, respetively. Proceeding with the integral over $\omega$ and $\phi$,

$$
\begin{gathered}
E_{\xi \eta \omega \phi} V_{t}\left(\xi, \eta, \omega, \phi, X_{t}, z_{t}\right) \\
=\pi^{-2} \sum_{l=1}^{L} \sum_{k=1}^{K} \sum_{j=1}^{J} \sum_{i=1}^{I} w_{i, \eta} w_{j, \xi} w_{k, \omega} w_{l, \phi} \cdot V_{t}\left(\sqrt{2} \sigma_{\eta}\left(\sqrt{1-\rho_{\xi \eta}^{2}} \eta_{j}+\rho_{\xi \eta} \xi_{j}\right)+\mu_{\eta}, \sqrt{2} \sigma_{\omega} \omega_{k}\right. \\
\left.\quad+u_{w}, \sqrt{2} \sigma_{\phi} \phi_{l}+u_{\phi} ; X_{t}, z_{t}\right)
\end{gathered}
$$

This model is expensive to compute. The number of nodes in the dynamic programming tree is $I \times J \times K \times L \times T \times S_{1} \times S_{2} \times S_{3} \times 2$, where $I, J, K, L$ are the nodes for different shocks as described above, $T$ is the maximum age that individual can live up to, $S_{1}, S_{2}$ and $S_{3}$ are the numbers of nodes for three state variables separately. Taking 80 as the total life periods and 5 nodes for each shock, the number of nodes for cash on hand is 60 , while the number of nodes for income and indexed wage is 10, separately. A non-uniform power function is used 
to map grid points into state values (details available from the authors). When the minimum stock investment threshold, $m$, is imposed we have two optimization problems at each state: one with bond investment only, the other with both bonds and stocks. Altogether, there are $I \times J \times K \times L \times T \times S_{1}^{\max } \times S_{2}^{\max } \times S_{3}^{\max } \times 2=600,000,000$ optimization problems. If any single optimization problem fails to converge, the entire program is repeated. 


\section{Appendix C}

Take the first-order condtion of Bellman equation

$V_{i, t}\left(X_{i, t}, z_{i, t}\right)=\max _{C_{i, t}, \alpha_{i, t}}\left\{U\left(C_{i, t}\right)+\beta\left[p_{t} \cdot E_{t} V_{i, t+1}\left(X_{i, t+1}, z_{i, t+1}\right)+b\left(1-p_{t}\right) \cdot E_{t} U\left(W_{i, t+1}\right)\right]\right\}$

Subject to

$$
\begin{aligned}
& X_{i, t+1}=R_{i, t}\left(X_{i, t}-C_{i, t}\right)+\left(1-h_{t+1}\right) Y_{i, t+1}^{d} \\
& X_{i, t}=W_{i, t}+\left(1-h_{t}\right) Y_{i, t}^{d}
\end{aligned}
$$

We have

$$
\begin{aligned}
& \frac{\partial V_{i, t}\left(X_{i, t}, z_{i, t}\right)}{\partial C_{i, t}} \\
= & U \prime\left(C_{i, t}\right)+\beta\left\{p_{t} \cdot E_{t}\left[V_{i, t+1} \prime\left(X_{i, t+1}, z_{i, t+1}\right) \cdot\left(-R_{i, t}\right)\right]+b\left(1-p_{t}\right) \cdot E_{t}\left[U \prime\left(W_{i, t+1}\right) \cdot\left(-R_{i, \text { (\$) (3) })}\right)\right.\right. \\
= & 0
\end{aligned}
$$

Change the equation, we have

$$
U \prime\left(C_{i, t}\right)=\beta\left\{p_{t} \cdot E_{t}\left[V_{i, t+1} \prime\left(X_{i, t+1}, z_{i, t+1}\right) \cdot R_{i, t}\right]+b\left(1-p_{t}\right) \cdot E_{t}\left[U \prime\left(W_{i, t+1}\right) \cdot R_{i, t}\right]\right\}
$$

According to the Envelope Therorem, the partial derivative with respect to $X_{i, t}$ is

$$
\frac{\partial V_{i, t}\left(X_{i, t}, z_{i, t}\right)}{\partial X_{i, t}}=\beta\left\{p_{t} \cdot E_{t}\left[V_{i, t+1} \prime\left(X_{i, t+1}, z_{i, t+1}\right) \cdot R_{i, t}\right]+b\left(1-p_{t}\right) \cdot E_{t}\left[U \prime\left(W_{i, t+1}\right) \cdot R_{i, t}\right]\right\}
$$

The right hand sides of Equations (34) and (35) are equal, which gives us

$$
U^{\prime}\left(C_{i, t}\right)=V_{i, t}\left(X_{i, t}, z_{i, t}\right)
$$

Thus, we rewrite Equation (34) as follows,

$$
U_{\prime}^{\prime}\left(C_{i, t}\right)=\beta p_{t} \cdot E_{t}\left[U \prime\left(C_{i, t+1}\right) \cdot R_{i, t}\right]+\beta b\left(1-p_{t}\right) \cdot E_{t}\left[U \prime\left(W_{i, t+1}\right) \cdot R_{i, t}\right]
$$




$$
C_{i, t}=U \prime^{-1}\left\{\beta p_{t} \cdot E_{t}\left[U \prime\left(C_{i, t+1}\right) \cdot R_{i, t}\right]+\beta b\left(1-p_{t}\right) \cdot E_{t}\left[U \prime\left(W_{i, t+1}\right) \cdot R_{i, t}\right]\right\}
$$

We define the Euler error as

$$
\begin{gathered}
C_{i, t} \cdot(1+\text { error })=U \prime^{-1}\left\{\beta p_{t} \cdot E_{t}\left[U \prime\left(C_{i, t+1}\right) \cdot R_{i, t}\right]+\beta b\left(1-p_{t}\right) \cdot E_{t}\left[U \prime\left(W_{i, t+1}\right) \cdot R_{i, t}\right]\right\} \\
\text { error }=\frac{U \prime^{-1}\left\{\beta p_{t} \cdot E_{t}\left[U \prime\left(C_{i, t+1}\right) \cdot R_{i, t}\right]+\beta b\left(1-p_{t}\right) \cdot E_{t}\left[U \prime\left(W_{i, t+1}\right) \cdot R_{i, t}\right]\right\}-C_{i, t}}{C_{i, t}}
\end{gathered}
$$

We then take a $\log _{10}$ of the error, the acceptable range is around -3 or smaller. 